\title{
Filosofía de la mente: Visión panorámica y situación actual
}

\author{
Carlos Beorlegui \\ Universidad de Deusto
}

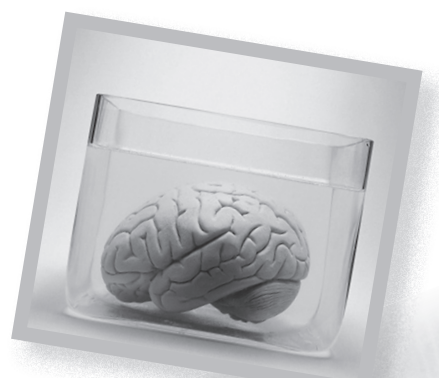

RESUMEN: La filosofía de la mente, esto es, la reflexión filosófica del ámbito de lo mental, ha experimentado un renacer en el ámbito académico estadounidense. No obstante, su trayectoria es anterior. En estas páginas, se ofrece un panorama de la filosofía de la mente, que incluye los distintos abordajes filosóficos de las relaciones alma-cuerpo, una visión panorámica de las diferentes posturas dentro de la moderna filosofía de la mente, los nuevos horizontes de reflexión dentro de la filosofía de la mente $y$, finalmente, una aproximación a las diferentes teorías sobre lo mental dentro del horizonte de los modelos antropológicos a los que pertenecen.

ABSTRACT: Philosophy of mind, i.e., the philosophical reflection about mind, has reborn in the American academic context. Nevertheless, its trajectory started from the Greek. The following essay offers a panoramic vision about philosophy of mind. This includes the philosophic perspectives on the body-mind relations, a panoramic vision of the modern philosophy of mind, the new horizons of reflection of such philosophy, and, finally, an approach to the theories about mind and the anthropologic models they belong to. 


\section{Introducción}

C

on esta denominación se suele hacer referencia a un nuevo rebrotar del interés por el tema de la mente y lo mental, nacido alrededor de los años setenta, en el ámbito norteamericano, subordinado al nacimiento de lo que se ha llamado psicología cognitivista, o ciencias cognitivas en general, y que retoma de otra manera el viejo tema de las relaciones alma-cuerpo que se remonta a los griegos. Y como consecuencia de la hegemonía cultural de los EE.UU., esta disciplina se está extendiendo con fuerza por Europa y el resto del mundo.

En general, la denominación filosofía de la mente es el conjunto de reflexiones filosóficas acerca de la naturaleza de lo mental, la relación mente-cerebro, y una serie de temas filosóficos similares, como es el referido a la naturaleza del Conocimiento mental, y como consecuencia la naturaleza de la realidad. Es decir, con motivo de la vuelta al interés por lo mental, las reflexiones han motivado un nuevo interés sobre la metafísica u ontología de la realidad, sobre la naturaleza del conocer (epistemología) y sobre el ser humano en general. Pero, en un sentido estricto, esta filosofía de la mente hace referencia más bien a la propuesta funcionalista de lo mental, esto es, a la teoría filosófica concomitante con el conjunto de las ciencias cognitivas, que Howard Gardner ${ }^{1}$ denomina el hexágono cognitivista: Psicología, antropología, neurofisiología, inteligencia artificial, lingüística, y filosofía, que se origina hacia los años setenta, pero que tiene sus primeros atisbos hacia los años cincuenta, momento en que se producen los primeros ataques al conductismo.

Pero, para ser justo con la amplitud que la expresión filosofía de la mente posee, no podemos ceñirnos al ámbito anglosajón, ni al rebrotar más reciente de esta problemática, sino que hemos de situar el problema tanto dentro del conjunto de la historia de la filosofía, como en conjunción con el modo como han tratado la cuestión los filósofos de la tradición continental. Por eso, el desarrollo de estas páginas tendrá los siguientes apartados: a) el despertar de la filosofía de la mente, o mejor, de la nueva filosofía de la mente; b) una breve historia del problema de las relaciones alma-cuerpo, desde los griegos hasta el conductismo; c) visión panorámica de las diferentes posturas dentro de la moderna filosofía de la mente; d) nuevos horizontes de reflexión dentro de la filosofía de la mente; e) y, para concluir, algunas pinceladas para enmarcar las teorías sobre lo mental dentro del horizonte de los modelos antropológicos de los que son deudoras. 


\section{El punto de arranque de la moderna o nueva filosofía de la mente}

L a filosofía moderna de la mente surge en oposición a las teorías antimentalistas del conductismo norteamericano. El conductismo fue, y sigue siendo, una teoría psicológica, o, más bien, una teoría científica sobre el comportamiento animal y humano, nacida al inicio del siglo XX de la mano de Watson y continuada después por su discípulo Skinner ${ }^{2}$. El conductismo, siguiendo las orientaciones de la recién nacida psicología científica, en la segunda mitad del siglo XIX, por iniciativa del alemán Wilhelm Wundt y del norteamericano William James, pretendió hacer del estudio del comportamiento una ciencia en su sentido más estricto. Con el intento de someter lo psíquico a los parámetros científicos, fundan ambos intelectuales diversos laboratorios de psicología para someter al rigor científico el conjunto de los contenidos de la mente.

Watson, Ilevando hasta el extremo las exigencias del método empírico, parte en sus reflexiones de una postura claramente antimentalista, $y$, por tanto, considera que sólo puede ser objeto de reflexión aquello que puede ser observado. De ahí que, a partir de entonces, el objeto de la psicología no será la psique o la mente (realidades para él no existentes), sino la conducta. Es la razón por la que se denominará a este campo del saber conductismo (no tanto psico-logía).
Ahora bien, dentro del conductismo se suelen hacer varias distinciones, entre el conductismo epistemológico y ontológico, y entre el científico y el filosófico o lógico.

a) Conductismo epistemológico y ontológico: el conductismo epistemológico parte de ignorar la existencia de lo mental (sin negar en principio que exista), reduciéndose las investigaciones al descubrimiento de las reglas de conducta. El ontológico, a su vez, parte del principio de que no existe lo mental, y por tanto no hay más materia de investigación que lo conductual.

b) Conductismo psicológico o científico y conductismo filosófico o lógico: el conductismo psicológico o científico se centra en el estudio científico de la conducta, para encontrar las leyes que la rigen. Es la línea desarrollada por Watson y Skinner, y sus discípulos. El conductismo lógico es la reflexión filosófica encaminada a purificar el lenguaje filosófico en clave conductista, reduciendo todo el lenguaje filosófico mentalista a estados o disposiciones conductuales. En este apartado se suelen situar Carl Hempel, G. Ryle y en parte Ludwig Wittgenstein, con su negación de la legitimidad de todo lenguaje privado ${ }^{3}$. Pero desarrollaremos sus tesis más importantes más adelante. 
El conductismo imperó hegemónicamente en el ámbito norteamericano durante toda la primera mitad del siglo XX, produciéndose hacia su mitad un abandono y descrédito fuerte del mismo, de la mano de las incipientes ciencias cognitivas. Para el conductismo, como hemos dicho, la conducta animal y humana se reduce a ser mera respuesta automática, o cuasi automática, a los estímulos del ambiente. Continuando las investigaciones de la escuela reflexológica del ruso Pavlov, y sus investigaciones sobre los reflejos condicionados, entiende Watson que la conducta animal se mueve bajo el esquema estímulo-respuesta (E-R). De ahí que se dedicara a investigar la conducta animal con sus famosos experimentos con ratas y laberintos. Claro que es consciente de que la conducta humana es más compleja, pero se debe a que el interior de la realidad corpórea posee unos mecanismos más complejos (una "caja negra") que el científico de la conducta tiene que descubrir. En concreto, Skinner entiende que en el esquema conductual, tanto del animal como del ser humano, se da una retroalimentación desde la respuesta del ambiente, esté compuesto por cosas o por personas. Así, construyó su teoría sobre el refuerzo: una conducta sale reforzada cuando el ambiente responde de una forma determinada. Además, distinguía entre el refuerzo positivo y el negativo, siendo más reforzador el positivo; esto es, los intentos de modificación de conducta son más eficaces y acertados cuando se premia una respuesta que cuando se la castiga.

El problema vendrá cuando diversas investigaciones de la conducta animal y humana fueron mostrando las insuficiencias de la teoría conductista para explicarla en su totalidad. Estas investigaciones fueron sobre todo en dos líneas diferentes: a) la etología, de la mano de K. Lorenz, Tinbergen, y demás, en Europa, mostrando las raíces innatas del comportamiento, y mostrando que la conducta animal es una síntesis de aspectos innatos y aprendidos ${ }^{4}$ y b) el conjunto de las ciencias cognitivistas, sobre todo la psicología, la neurofisiología y la lingüística generativa (N. Chomsky), que indicaban que los procesos conductuales son tan complejos que no pueden explicarse con el simple esquema estímulo-respuesta. Se podía advertir claramente que conductas tan complejas como tocar el piano, o jugar al tenis, o sobre todo aprender un lenguaje, sólo podían explicarse con un programa innato interno que se anticipara a los movimientos y datos estimulares, y los organizara de forma autónoma. Es decir, no cabía más alternativa que volver a recuperar la hipótesis de lo mental, como estructura interna autónoma.

Es así como se produce el renacimiento con fuerza de las tesis mentalistas, el nacimiento del cognitivismo. Pero en la recuperación de lo mental con el cognitivismo 
y la nueva filosofía de la mente, los teóricos más conspicuos y formados advierten también que sus reflexiones no nacen de cero, sino que empalman con toda una tradición filosófica que se remonta a la época de los griegos e incluso antes $^{5}$. Vamos a verla de forma muy esquemática.

\section{La historia del problema del alma y de las relaciones alma-cuerpo}

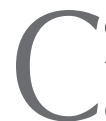
omo sabemos, la historia de la filosofía parte de la existencia del alma como ingrediente fundamental de la realidad humana. Y nace más bien en el horizonte de las diversas doctrinas religiosas, con objeto de dotar al ser humano de una diferencia esencial con respecto a los animales y a los objetos inanimados. De ahí que se ha solido distinguir, a la hora de entender las afirmaciones sobre el alma, entre el nivel funcional y el óntico ${ }^{6}$.

- El aspecto funcional: se habla del alma en función de afirmar y defender la dignidad ética del ser humano. Decir que el ser humano tiene alma equivale simplemente a decir que tiene algo que le diferencia de las demás realidades, sin tener la pretensión de definir qué sea eso del alma.

- En cambio, el aspecto o dimensión óntica se encarga de investigar el contenido óntico y ontológico de eso que denominamos alma.

En esta literatura religiosa o mítica, no se habla tanto de la mente, sino del alma, dándole un contenido ontológico denso, aunque no todas las teorías defienden los mismos presupuestos. Veamos un recorrido rápido por las diferentes teorías.

3.1. Posturas pre-filosóficas que defienden una concepción unitaria del hombre ${ }^{7}$

Se suele pensar que la primera concepción antropológica en este tema suele ser dualista, y no es así. En las concepciones anteriores al dualismo platónico, se parte de una concepción unitaria del ser humano. Es el caso tanto de la mentalidad homérica como de la bíblica.

a) La mentalidad homérica

Utiliza los mismos conceptos que la filosofía griega clásica (psyché: alma y soma: cuerpo), pero su significado es muy diferente. Así, la psyché no significa el alma, sin más, en oposición al cuerpo, ni el núcleo personal del "yo", sino más bien el soplo vital que abandona al hombre a través de la boca y las heridas. Tampoco el soma es el cuerpo, en oposición al espíritu, sino el cadáver, abandonado por la psyché. El cuerpo homérico es entendido más bien como una yuxtaposición de órganos y de elementos separados. 
b) La antropología bíblica

La concepción antropológica semita o hebrea no es dualista, sino que se concibe al ser humano como una radical unidad, aunque vista bajo diferentes aspectos o puntos de vista. En el Antiguo Testamento se utilizan tres conceptos antropológicos de interés: basar, nefes y rúah.

Basar (sarx, caro, carne): no significa el cuerpo en oposición al alma, sino el hombre entero bajo el aspecto de débil y frágil. "Nuestra carne" significa también nuestra parentela. $Y$ al decir "el Verbo se hizo carne", se quiere decir que se hizo frágil, que asumió nuestra condición humana.

Nefes (psyché, anima, alma): originariamente significaba el cuello, la garganta, respiración, aliento vital, y luego se identificó con la sangre. Por ello, los judíos tienen prohibido beber la sangre. Así, pues, el hombre es nefes, esto es, un ser viviente. $\mathrm{Y}$ por eso también sirve para expresar el pronombre yo, tú, él (Así: "Anima mea tristis est usquead mortem", dice Jesús en Getsemaní. O la expresión de San Francisco de Sales: "Da mihi animas, caetera tolle").

Ruah (pneuma, spiritus): no es una sustancia en oposición a la materia, sino aquello que hace al hombre capaz de abrirse a la escucha de Dios. Por tanto, indica una relación especial del hombre con Dios, un carisma que capacita al ser humano para ejercer una tarea en el ámbito de la salvación. Por tanto, como señala J. Gevaert, "Ruah no indica una función espiritual inherente al hombre natural, sino la esfera del influjo de Dios" ${ }^{\prime \prime}$.

Lo mismo podemos decir del Nuevo Testamento, que sigue manteniendo la misma estructura unitaria del ser humano, como puede verse en los escritos paulinos. Por tanto, en los escritos bíblicos, no se pretende ofrecer unas reflexiones de tipo ónticoantropológico, sino orientaciones sobre la condición religiosa del ser humano. Así, la oposición sarx-pneuma (corpus-spriritus) no hace referencia a la oposición platónica cuerpo-espíritu, sino a dimensiones diferentes del ser humano. Es decir: cuerpo significa la condición natural del hombre, y espíritu, su dimensión espiritual, el hombre bajo la llamada de la gracia. No son, pues, dos componentes ontológicos, sino dos dimensiones de la realidad humana: el hombre terreno frente al hombre redimido.

\subsection{Las posturas de la filosofía griega: el dualismo platónico y el hilemorfismo aristotélico ${ }^{9}$}

Dentro de la tradición griega se encuentran dos posturas diferentes: el dualismo platónico y el hilemorfismo aristotélico.

a) El dualismo platónico ${ }^{10}$

Platón estaba influenciado en sus teorías por los ritos órficos (en 
honor del dios Orfeo), que adoraban a las fuerzas de la vitalidad natural, y partían de un dualismo de vida-muerte, espíritu-materia, inmanencia-trascendencia. El orfismo hablaba de preexistencia, caída y transmigración de almas.

La concepción platónica de la realidad está basada en un dualismo ontológico que supone el dualismo antropológico. Su dualismo ontológico defendía que la realidad que vemos es sólo apariencia, mientras que la realidad ideal no la vemos, porque vive en un mundo aparte: el mundo de las ideas. Su dualismo antropológico consistía en defender que el hombre es por esencia una planta celestial ${ }^{11}$. Así, el ser humano está compuesto por un cuerpo y un alma, que tras vivir un tiempo en el mundo de las ideas, ha sido condenada a vivir en un cuerpo durante su vida terrestre. De ahí que utilice las metáforas de la nave y su piloto (ciberneta), del caballo y su jinete. De ahí que aprender sea sólo recordar (función mayéutica: referencia a la tarea de la partera, pasaje del Menón). Así, con la muerte del hombre, muere el cuerpo, pero el alma puede volver al mundo de las ideas y seguir existiendo. Así, se defiende de este modo la inmortalidad del alma. Por tanto, el alma espiritual tendrá que purificarse durante su vida para poder liberarse del cuerpo, a través de sucesivas reencarnaciones. En conclusión, "el acento principal en el dualismo platónico no se encuentra por tanto en la división ontológica entre cuerpo y alma, sino en el significado del cuerpo y de la materia en la realización religiosa y moral del hombre"12.

De todos modos, se suele decir que Platón fue evolucionando en sus posturas, y en las obras de su madurez, el Timeo y las Leyes, presenta una concepción antropológica menos dualista, no insistiendo tanto en la separación de estos dos componentes antropológicos, sino en su unidad e interrelación inevitable a pesar de la diferencia. De todos modos, la concepción dualista platónica tuvo una influencia esencial y profunda en la concepción dualista asentada a lo largo del cristianismo medieval y posterior. De ese modo, se aprecia y valora lo espiritual, y se menosprecia por el contrario el cuerpo, lo material.

\section{b) El hilemorfismo aristotélico ${ }^{13}$.}

Aristóteles se desmarca del pensamiento de su maestro Platón, tanto en el dualismo ontológico como en el antropológico, tras haber defendido el dualismo en su primera etapa. Para Aristóteles, cada cosa está compuesta no por dos sustancias autosuficientes, sino por dos principios ontológicos: la materia prima (hylé) y la forma sustancial (morfé). La materia prima es aquello de que está compuesta una cosa; y la forma sustancial, aquello que hace que una cosa sea lo que es y no otra cosa. Ninguno de estos dos elementos ontológicos puede existir por separado, sino que conforman una unidad necesaria e inseparable. 
Aristóteles aplica esta teoría ontológica al ser humano: el ser humano está compuesto también por dos principios ontológicos, no por dos sustancias autosuficientes: la materia prima y la forma sustancial. Por tanto, el ser humano es una unidad inseparable, de modo que cuando muere, muere el hombre entero, no pudiéndose defender por tanto la tesis platónica de la inmortalidad del alma. La materia no existe nunca sin una forma determinada, y la forma no existe sino como forma de una determinada materia. De este modo, quedan superadas las dificultades de todo dualismo a la hora de tener que explicar cómo se produce la relación de los dos componentes antropológicos. Esto no significa aceptar una concepción materialista del ser humano. Aristóteles no era materialista, aunque algunos discípulos del filósofo griego han deducido de esta estrecha relación entre cuerpo y alma la negación de la inmortalidad humana.

Ahora bien, en Aristóteles hay un par de ambigüedades en su teoría hilemórfica: por un lado, utiliza a veces la palabra cuerpo en dos sentidos diferentes: para indicar al hombre entero (la materia más la forma, lo que sería la postura más adecuada), con lo cual el cuerpo (vivo) es ya materia informada, o para indicar sólo la materia prima, la que forma parte del organismo vivo y está informada por el alma, la forma. El peligro de esta segunda acepción es acercarse peligrosamente al dualismo platónico; y, por otro lado, al distinguir dos tipos de entendimiento: el agente (el nous) y el pasivo, llega en algunos momentos a defender un entendimiento agente supra personal, de un cierto carácter divino que perviviría, por tanto, a la muerte de los individuos. Es lo que explica que un discípulo posterior de Aristóteles, el filósofo islámico Averroes, defendiera la teoría del panpsiquismo.

Para Aristóteles, el entendimiento agente no tiene necesidad para actuar del soporte corpóreo, por lo que no parece poder considerarlo como expresión de las funciones orgánicas ni como una parte del alma. El nous parece distinto del alma, ya que le viene al hombre de fuera, de instancias externas, por lo que parece tener un carácter divino, y podría existir sin el cuerpo humano y ser considerado inmortal. En cambio, el alma, en la medida en que está ligada por naturaleza a su propio cuerpo, no puede existir separada de él.

\subsection{La época medieval}

Durante la Edad Media, las diferentes escuelas escolásticas se dividieron en seguidores de Platón y de Aristóteles. Y predominó la orientación platónica dualista, impregnando toda la mentalidad antropológica popular. La línea franciscana siguió los planteamientos de Platón (y de San Agustín) y se adscribió más bien a las tesis dualistas. En cambio, Santo Tomás trató de cristianizar la filosofía de Aristóteles. Para Santo Tomás ${ }^{14}$, al igual que para Aristóte- 
les, el hombre es la síntesis de dos principios ontológicos: la materia y la forma, que forman una unidad indisoluble. De tal modo que, al morir el hombre, muere todo entero. Pero sus planteamientos teológicos le inclinaron a adoptar también un cierto dualismo, al admitir que el alma es un espíritu (sustancia espiritual) de orden inferior, creado directamente por Dios, y que necesita apoyarse en una realidad corpórea. $\mathrm{Y}$ tras la muerte, ese alma puede existir como alma separada, pues es incorruptible. Aunque esa existencia es contraria a su naturaleza, puesto que el alma ha sido creada para animar a un cuerpo. Pero, como vemos, las creencias teológicas (la fe en la resurrección y en una segunda vida) le orientan hacia una cierta concepción dualista de fondo.

\subsection{El dualismo cartesiano ${ }^{15}$}

Las tesis dualistas volvieron a reproducirse con fuerza por medio de René Descartes, pero con planteamientos diferentes que en el caso de Platón. Su dualismo ha sido fundamental para conformar una idea del hombre durante toda la época moderna. Pero el fundamento del dualismo antropológico cartesiano tiene raíces un tanto diferentes al platónico. Si en el filósofo griego la justificación de su dualismo era mítica, ética y metafísica (influencias órficas), en Descartes la justificación era más bien de tipo epistemológi- co. Descastes estaba preocupado por el problema de la fundamentación de las ciencias. Así, su dualismo pretendía prestar su fundamento teórico tanto a la filosofía como a la física y a todo tipo de explicación científica sobre el cuerpo. "Por tanto, como dice Gevaert, su dualismo es un dualismo ontológico con función metodológica"16.

Así, el cuerpo, radicalmente diferente del alma, funciona con principios distintos a los de ésta, porque está organizada con elementos materiales. No se necesita ninguna alma, como defendía el hilemorfismo, para explicar el funcionamiento del cuerpo. Por eso, Descartes recurre a la hora de entender el cuerpo humano a la imagen de la máquina; de ahí que su teoría fuera denominada mecanicista. El cuerpo no es más que realidad atómica, física, extensa (res extensa), con lo que dejaba vía libre a las ciencias de lo corpóreo, y las defendía de la prohibición inquisitorial de experimentar con el cuerpo humano, aunque fuera ya cadáver.

En cambio, el alma humana es una realidad ontológica totalmente distinta del cuerpo. Es conciencia pura, res cogitans, y por ello transparente a sí misma, necesitada de razonar para aclarar su propia realidad. Y, de este modo, la conciencia o res cogitans constituye la esencia del ser humano, como afirma el propia Descartes:

"Conocí por ello que yo era una sustancia cuya esencia y naturaleza toda es pensar, y que no necesita, para ser, de lugar alguno, ni depende de cosa alguna material; de suerte que este yo, es de- 
cir, el alma por la cual yo soy lo que soy, es enteramente distinta del cuerpo y hasta más fácil de conocer que éste, y, aunque el cuerpo no fuese, el alma no dejaría de ser cuanto es"17.

A pesar de estas afirmaciones, Descartes no defendió el dualismo absoluto, sino una real interdependencia entre ambas sustancias, cuerpo y alma o conciencia. Incluso llega a decir que las imágenes del barquero y la barca le parece una relación demasiado externa e inadecuada. La relación entre ambas la entendía como una relación esencial, sin la cual no existiría el ser humano. Pero el problema del dualismo siempre ha sido su dificultad, e incapacidad, de poder explicar las interacciones alma-cuerpo. En el caso de Descartes, trato de explicarlo a través de su teoría de la glándula pineal, presente en el encéfalo humano. Otros autores trataron de dar explicaciones diferentes. Es el caso, en primer lugar, de Malebranche con su teoría ocasionalista. El ocasionalismo de Malebranche defiende que el intermediario entre el alma y el cuerpo es Dios, quien con ocasión de una decisión de un alma actúa en el cuerpo correspondiente para hacerle ejecutar esa decisión. Pero eso suponía postular la intervención de Dios en el ámbito de lo mundano, en la cadena de las causas segundas, haciéndole intervenir como un Deus ex machina, y postulando un milagrerismo permanente.

Por eso, Leibniz propuso una hipótesis diferente: la armonía preestablecida, consistente en postular que desde el primer instante de cada ser humano se da una especie de sincronización entre su cuerpo y su alma, de modo que a cada decisión anímica se daría una correspondiente respuesta en el cuerpo, y viceversa. Esta teoría, que evitaría la intervención milagrera permanente de Dios, lo hace al precio de negar o poner en peligro la libertad humana, puesto que si las cosas son como piensa Leibniz, los seres humanos somos unos autómatas perfectamente programados para tomar decisiones y realizar actos previamente programados por nuestro creador.

A partir de ahí, la historia de la filosofía se fue diluyendo en disputas y en disquisiciones interminables sobre el problema de compatibilizar la libertad humana y el determinismo de las leyes mundanas, a las que pertenece nuestra condición corpórea. En esta línea se sitúan las reflexiones de Kant, de Hegel y de otros filósofos sobre la libertad. Todas estas dificultades y las respuestas tan peregrinas de algunos filósofos, unidas al avance de las ciencias, hicieron que el tema de las relaciones alma-cuerpo se fuera quedando obsoleto y desapareciera de las discusiones de interés de los grandes filósofos. Pero las cosas tomaron un rumbo diferente a partir de la eclosión de las ciencias humanas durante el siglo XIX. 


\section{El siglo $X I X$ y el surgimiento de las ciencias \\ humanas}

$\mathrm{D}$ urante el siglo XIX se produce el despertar de las Ilamadas ciencias humanas, que tratan de conseguir un estatuto científico que les asemeje, o no les deje en un segundo lugar vergonzante, respecto a las ciencias naturales, que habían conseguido su madurez a partir del siglo XVII. El acontecimiento clave fue la teoría de la selección de Darwin, proponiéndose como motor y pieza explicativa del proceso evolutivo, y situando al ser humano dentro del ámbito de la biosfera y como una pieza más de la realidad material.

A nosotros nos interesa aquí el proceso de desarrollo de la psicología científica, de la mano de Wundt y James. Al igual que en el resto de las parcelas de las ciencias humanas, la psicología científica pretende investigar el ámbito de lo mental desde parámetros científicos, comenzándose a dar la vuelta a la mentalidad cartesiana. Es decir, si para Descartes era evidente que lo que identifica al ser humana es su conciencia, su alma, siendo la realidad corpórea un elemento secundario, para la nueva ciencia psicológica lo evidente es lo que puede ser observado y sopesado objetiva y empíricamente. Al mismo tiempo, los métodos de acercamiento a la realidad de lo psíquico son diferentes: al método introspectivo propio de Descartes se contrapone un método empírico. Para este método, lo evidente y real es el comportamiento humano y su posible medición, y lo problemático será precisamente el acceso introspectivo a la interioridad de la conciencia.

Para estos primeros psicólogos científicos servirá todavía el acercamiento introspectivo a lo mental, aunque sopesando sus logros con los métodos experienciales de las ciencias, pero el conductismo posterior cortará por lo sano y no considerará aceptable más que la mera descripción y observación externa y científica de la conducta. De este modo, se cumple con exactitud la afirmación de J. Gevaert: "no podemos menos de aludir al hecho de que ha sido precisamente el dualismo extremo el que más ha contribuido a la afirmación del materialismo"18.

\section{Una doble tradición investigadora: la continental y la anglosajona ${ }^{19}$}

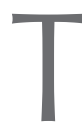
ras el siglo XIX, se dividen los planteamientos de cara a la estrategia más adecuada y legítima para el acercamiento al tema de lo mental y de las relaciones alma-cuerpo o mente-cuerpo:

* Por un lado, en los ambientes continentales (Alemania y Francia, sobre 
todo) se sigue reflexionando desde parámetros filosóficos tradicionales, considerando como válido el método introspectivo de acercamiento al problema de lo mental. En esta línea están las reflexiones siguientes, sobre las que no nos vamos a extender demasiado. En primer lugar, hay que destacar a Husserl y su filosofía del yo empírico y trascendental ${ }^{20}$. En el pensamiento de Husserl sobre la subjetividad o el yo, comenzó intentando alcanzar la esencia del yo (reducción fenomenológica), pero en su dimensión trascendental ${ }^{21}$. Ahora bien, en los últimos años de su vida, Husserl fue descubriendo la naturaleza mundana e histórica de la subjetividad, y se abre a la reflexión del Lebenswelt (mundo de la vida), origen de las teorías de Heidegger sobre el ser-en-el-mundo. Un puesto importante en esta tradición continental lo ocupa Maurice Merleau-Ponty y sus reflexiones sobre la relación alma-cuerpo, con sus teorías sobre el cuerpo propio. En su obra Fenomenología de la percepción ${ }^{22}$, advierte la radical ambigüedad de la realidad humana, como síntesis de racionalidad y de corporalidad. El cuerpo no es una realidad al margen de mí, sino que me es accesible como cuerpo externo (Körper) y como cuerpo propio (Leib). Así, tengo cuerpo y soy cuerpo a la vez, formando esta dualidad una unidad indisoluble. Así, Merleau-Ponty entiende que la propia racionalidad está impregnada de irracionalidad, de corporalidad, por lo que al ser humano no lo podemos ni entender ni experimentar al margen de la confluencia de ambas perspectivas. Esto tiene repercusiones ontológicas, epistemológicas, éticas, etc. ${ }^{23}$. Frente a esta postura unitaria, Sartre defenderá posturas dualistas (en-sí y para-sî́) ${ }^{24}$.

A su vez, las investigaciones psicoanalíticas de Freud, Jung, Lacan y demás discípulos sobre la estructura de la conciencia, el inconsciente, la interpretación de los sueños, los arquetipos, etc., pretenden hallar una vía científica al estudio de la psique por el camino de la introspección y el análisis de la conciencia ${ }^{25}$. En esta línea, el cuerpo y sus tendencias cobran más importancia que lo mental, que queda reducido a funciones superiores de las tendencias corpóreas. Toda esta línea de reflexión no será seguida ni aceptada por la línea anglosajona, más anclada en parámetros empíricos para acometer el acceso a lo mental.

* Por otro lado, la tradición anglosajona, cuyo fruto más importante será el conductismo, basado en una concepción materialista de la realidad y en las orientaciones del positivismo lógico y de la filosofía analítica del Círculo de Viena y seguidores. Vamos a seguir a continuación esta línea de pensamiento, puesto que es en ella donde surge la denominada nueva filosofía de la mente, pero sin olvidar las aportaciones de la línea continental. 


\section{El conductismo psicológico y el conductismo \\ lógico}

Y a hicimos referencia a este movimiento en los apartados iniciales, por lo que aquí nos limitaremos a los apartados que afectan más directamente al tema que nos ocupa.

Señalamos ya que el conductismo, Ilevando hasta sus últimas consecuencias el método científico de las ciencias naturales, parte de la no evidencia de la conciencia interior, centrando su reflexión en el análisis de la conducta. De todos modos, veíamos cómo hay que distinguir entre un conductismo apoyado en un reduccionismo metodológico y un conductismo basado en un reduccionismo ontológico. El primero no se cierra a la posible existencia de la conducta, pero prescinde de ella en sus investigaciones. En cambio, el segundo parte de la afirmación explícita de su no existencia.

Pero también hacíamos referencia a la división, más pertinente para lo que nos interesa, entre un conductismo científico/psicológico y el conductismo filosófico/lógico. Vamos a ampliar esta distinción y señalar lo básico de ambas líneas de reflexión.

\subsection{El conductismo científico o psicológico}

Es la línea original, nacida de la mano de Watson y Skinner, como científicos más significativos, empeñados en la investigación de la conducta, tanto animal y humana. Su tesis, como ya dijimos, consiste en considerar que no existe una diferencia cualitativa entre el comportamiento animal y humano.

Para ellos, el esquema básico que rige la conducta es la relación entre estímulo y respuesta (E-R), puesto que los seres vivos nacen como tabula rasa, y orientan su conducta en relación con los estímulos y respuestas a su conducta recibidas de su entorno. En el ser humano ocurriría lo mismo, aunque los mecanismos de respuesta sean más sofisticados. Dijimos que seguían las huellas de la escuela reflexológica del ruso Paulov. Watson defendió el esquema ambientalista en su sentido más extremo, llegando a decir: "Dadme cualquier niño y haré de él lo que quiera: médico, mendigo, criminal, ingeniero...".

Skinner complejificó el esquema conductual, introduciendo el concepto de refuerzo, indicando que es más fructífero para modificar y orientar la conducta el refuerzo positivo (recibir premio y gratificación a una respuesta) que el negativo (castigo por una respuesta errónea). Skinner negaba, por tanto, la libertad humana, considerándola como el nombre de una equis o concepto obsoleto para un aspecto de las leyes conductuales todavía no esclarecido $^{26}$. Igualmente, construyó su teoría utópica sobre una sociedad 
humana basada en una educación programa siguiendo los parámetros conductistas ${ }^{27}$.

Ya dijimos que el conductismo, debido a sus importantes éxitos a la hora de mostrar la estructura conductual, imperó de forma absoluta en el ámbito de la Psicología norteamericana durante prácticamente toda la primera mitad del siglo XX.

\subsection{El conductismo lógico ${ }^{28}$}

Esta línea filosófica partía de los mismos parámetros científicos que el conductismo psicológico, completados con las tesis de la filosofía analítica y el neopositivismo del primer Wittgenstein y del Círculo de Viena. Así, su línea filosófica consistirá en dejar de lado planteamientos metafísicos y purificar el lenguaje filosófico de todo rastro de vestigios metafísicos trasnochados. Por tanto, con relación a la temática que nos ocupa, encaminarán todos sus esfuerzos a mostrar que el concepto de mente es un rastro metafísico inverificable. En ese sentido, consideraban que no tienen sentido afirmaciones de tipo mentalista como "yo estoy triste", "yo tengo miedo", "Antonio es valiente", etc., que suponen aceptar un núcleo ontológico (el yo, la mente o la conciencia) a la que se le atribuyen unas cualidades o estados mentales.

Todo su empeño consistirá en explicar y sustituir todo ese trasnochado lenguaje mentalista en clave de estados o disposiciones conductuales. Un de las expresiones más representativas del conductismo ló- gico es Gilbert Ryle, con su célebre libro The Concept of Mind $^{29}$, en el que hará célebre la crítica al dualismo de Descartes con la célebre expresión y diagnóstico de constituir su teoría de la conciencia una especie de fantasma en la máquina. Para Ryle, al igual que para los filósofos analíticos y los positivistas lógicos, el lenguaje está lleno de conceptos abstractos que no significan nada. Por ejemplo: Universidad, batallón, bosque, etc. $Y$ lo mismo pasa con los estados mentales. Es decir, cuando se visita una universidad, no percibimos más que edificios, personas, árboles, pero la universidad en abstracto no existe. Como tampoco un batallón de soldados, o un bosque de árboles. Lo mismo ocurre con los supuestos estados mentales. Todas esas entidades se pueden explicar y sustituir por estados o disposiciones conductuales. Para ello, trasponen la descripción de las cualidades de las cosas materiales a la conducta humana. Por ejemplo, decir que el azúcar es soluble no significa que haya una entidad ontológica a la que hay que atribuir una cualidad, ser soluble. Simplemente se quiere indicar una disposición a comportarse de una manera determinada, si se dan determinadas condiciones ambientales. Esto es, decir que el azúcar es soluble es lo mismo que decir que: "si se introduce un trozo de azúcar en un líquido, el azúcar se disolverá".

Lo mismo podemos decir de cualquier estado mental: o bien designa una descripción de un es- 
tado conductual (Pedro es miedoso, significa que está expresando los rasgos físicos propios de tener miedo); o bien, designa una disposición conductual (si Pedro está en una situación de indefensión ante algo, mostrará rasgos comportamentales que denominamos tener miedo, propios de un miedoso). La dificultad mayor para el conductismo lógico es el problema de los qualia, esto es, de las experiencias interiores que todos tenemos ante una situación concreta. Por más que se han esforzado en explicitar estas situaciones en clave de estados o disposiciones conductuales, resultan sus argumentos muy poco convincentes.

Se suele situar dentro del conductismo lógico a Wittgenstein, con su teoría sobre la imposibilidad de un lenguaje privado, en la medida que ello negaría la posibilidad de describirse intersubjetivamente una experiencia interior, personal, introspectiva. Pero Wittgenstein no fue tan tajante a la hora de negar la existencia de la mente, contentándose con advertir la dificultad de compaginar la experiencia interior introspectiva y la radical e inevitable condición social e interpersonal de todo lenguaje con sentido.

Algunas de las limitaciones que se han achacado al conductismo son las siguientes: sus descripciones son muy generales $y$, por tanto, dudosamente elucidatorias; dos agentes pueden diferir de sus estados psicológicos pese a la similitud de sus respuestas conductuales (decirlo de otro modo); hay estados mentales internos no acompañados por tales respuestas; y el problema de los qualia. Todos estos ataques recibidos llevan aparejados dos tipos de conclusiones: a) la necesidad de reconocer la relevancia de los estados internos de los agentes y sus conexiones causales; y b) dudar del interés teórico de los planteamientos filosóficos que se centran en el análisis del significado de los términos y oraciones mentales.

\section{La vuelta de las posturas mentalistas.}

L

a caída del conductismo supuso la recuperación y el resurgir del concepto de lo mental, reproduciéndose un abanico de posturas explicativas tanto del concepto de mente como de la relación mente-cuerpo. El conductismo fue atacado y superado directamente por dos nuevas teorías sobre lo mental, que surgen en suelo norteamericano: a) la teoría de la identidad (TI) o monismo/materialismo fisicalista, y b) por el funcionalismo, la filosofía de la mente propia del cognitivismo. Pero también se irán defendiendo otras posturas y fórmulas paralelas. Todas ellas se pueden clasificar en torno a tres posturas, que iremos presentando sucesivamente:

a) Monismos materialistas o reduccionistas. 
b) Dualismos interaccionistas.

c) $Y$ posturas intermedias o sintéticas, que tratan de conjugar la unidad del ser humano con la correlación de los dos componentes, la mente y el cuerpo.

Dentro de este apartado se sitúan varias teorías:

c.1) El funcionalismo.

c.2) Los diversos emergentismos.

c.3) El estructurismo.

c.4) Y el neo-hilemorfismo.

Vamos a ir describiendo brevemente cada una de estas posturas.

\subsection{La teoría de la identidad ${ }^{30}$ o monismo fisicalista ${ }^{31}$}

Tanto la TI como el funcionalismo fueron, como hemos dicho, las teorías que más directamente se desmarcan y atacan las insuficiencias del conductismo y adoptan posturas mentalistas. Para estas dos teorías, la mente y los estados mentales son realidades reales y objetivas, aunque difieran en la forma de entender estas realidades. Ya indicamos que numerosas investigaciones en diferentes campos científicos iban aportando elementos para desmentir las tesis exclusivamente ambientalistas del conductismo. El aspecto interno e innato de la estructura comportamental se hacía cada vez más evidente. Así, los avances en el estudio del cerebro (neurofisiología) mostraban que existía en el interior del cerebro una organización interna autónoma que intervenía en el origen y desarrollo de la conducta.
Es lo que dará origen a la llamada teoría de la identidad (TI) o monismo fisicalista.

Lo mismo ocurre desde el conjunto de las ciencias cognitivas: se advierte que existe el ámbito de lo mental, como estructura interna, que constituye el autor y sujeto de la conducta, que no se limita a responder miméticamente a los estímulos de fuera. Así surge el funcionalismo, como teoría que distingue entre el soporte físico de lo mental (hardware, cerebro), y la programación lingüística del mismo (software). Vamos a detenernos en este apartado en al primera de estas teorías. La TI o monismo fisicalista es un conjunto de teorías, que aunque tienen diferentes denominaciones $^{32}$, y se diferencian en aspectos menores, tienen en común unas líneas fundamentales que vamos a señalar. Los trabajos de esta amplia corriente denominada TI se deben a los filósofos australianos U. T. Place y J. J. C. Smart, y al filósofo alemán H. Feigl. La obra de Smart ${ }^{33}$ fue la que posiblemente ejerció la mayor influencia. La TI fue la que gozó de mayor aceptación durante la década de los sesenta.

Nos vamos a detener en exponer el monismo o materialismo fisicalista de H. Feig ${ }^{34}$. Su teoría se puede sintetizar en tres afirmaciones ${ }^{35}$ : a) La mente y los estados mentales son realidades objetivas; b) La mente es el cerebro; c) El cerebro, y en general toda entidad biológica, es en último análisis una estructura física. 
Con la primera tesis se alejan del conductismo y se sitúan en una postura mentalista. No sólo se dan estados mentales, sino que también es real el centro que aglutina esos estados, la mente y el yo, la unidad de la conciencia, que funciona como eslabón en la cadena central de nuestra conducta. Eso no significa, según Feigl, que "subjetivo" quiera decir "no objetivo", puesto que lo subjetivo se puede expresar e inferir desde fuera por otro observador. Así, "subjetivo" y "objetivo" pueden intercambiarse.

La segunda tesis es la determinante y específica de esta postura. Para Feigl, la mente no es una realidad al margen del cerebro, sino que equivale al nombre que se le da al funcionamiento del cerebro. Si no fuera así, iríamos contra el principio de economía (the rule of parsimony) propio de la ciencia, defecto de todo dualismo. El problema es que habría que ver si la neurofisiología está capacitada para explicar todo aquello de que es capaz el ser humano. Feigl opina que sí, pensando que todo tipo de conducta se puede explicar desde un elemento cerebral. Incluso afirma que la conducta humana sería totalmente predecible si domináramos totalmente el funcionamiento del cerebro. Llega incluso a soñar con la posibilidad de crear una máquina, denominada "cerebroscopio", en la que se reflejase físicamente la situación del cerebro como expresión empírica de cualquier estado mental. Por tanto, y esto es lo central de esta teoría, para Feigl es equivalente la experiencia interior que cada sujeto tiene de un estado mental y la visión objetiva que el científico u observador externo tiene del estado cerebral correspondiente. Se trataría, sin más, de dos caras de la misma realidad.

Feigl es consciente de que con esta afirmación está borrando la barrera entre lo subjetivo y lo intersubjetivo, y acepta cruzar esa barrera, porque considera que "lo privado es susceptible de una descripción pública" (intersubjetiva). Pero esta tesis está muy lejos de resultar evidente, puesto que, como hemos dicho, la experiencia interior de cada sujeto, los llamados qualia, difícilmente pueden reducirse y considerarse equivalentes a su expresión cerebral externa (como tampoco a su expresión o disposición conductual, como veíamos en el conductismo).

La afirmación central de la TI consiste en defender que los fenómenos mentales son idénticos a estados neurológicos del sistema nervioso central. Un ejemplo que utilizan mucho estos autores: el dolor es numéricamente idéntico a disparos de las fibras-c del cerebro. $Y$ es importante recalcar que la identidad de esta frase hay que entenderla en sentido estricto. No se trata de afirmar sólo que dolor y disparos de fibras-c son realidades contiguas, esto es, que se suceden de modo paralelo. No, se trata de afirmar la identidad estricta. Es la misma identidad que existe en frases como "El lucero matutino es el 
lucero vespertino" (Venus), "El agua es $\mathrm{H}_{2} \mathrm{O}$ ", "Los genes son segmentos de moléculas de ADN", o "El calor es energía cinética media".

Insistiendo en este punto, la TI no afirma sólo que ambas partes de la igualdad signifiquen lo mismo, sino que son lo mismo. Así, se intenta reducir de este modo la Psicología a la Neurofisiología, Ilevando de fondo este intento la idea de una futura unificación de la ciencia.

Las críticas más importantes a este modo de entender las cosas han sido las siguientes:

a) Aplicando la distinción que hace Frege entre denotar y significar, tenemos que advertir que las expresiones anteriores (por ej.: "El lucero matutino es el lucero vespertino") aunque tienen el mismo denotatum, en este caso el planeta Venus, no tienen el mismo contenido significativo (es decir, el modo con que cada expresión presenta el denotatum). Cada uno de los dos términos de la supuesta igualdad hacen referencia a dos niveles distintos de la realidad: el fenoménico (el acceso introspectivo y cualitativo) y el neurofisiológico (objetivo y científico), que difícilmente podemos considerar totalmente idénticos. Es posible que en ciertas frases que hemos señalado más arriba puedan ser aceptadas en su profundidad, por ej., el referido a los genes. Pero no es tan aceptable el referido a Venus, y menos aún la identidad entre dolor y disparos de fibras-c. Estas dificultades hicieron que la TI fuera abandonada, para plantear la alternativa del eliminativismo $^{36}$, consistente en eliminar, dentro de la propuesta identitaria de la $\mathrm{TI}$, la primera parte, esto es, los estados mentales, reduciéndolos a meras descripciones de los estados cerebrales correspondientes.

b) La segunda dificultad se refiere a lo que se denomina el problema de la realizabilidad variable. Es decir, la plasticidad del cerebro es tal, que no se descarta que un mismo estado cerebral permita diversos estados mentales; y al revés, un mismo estado mental puede estar representado o realizado por diversos estados cerebrales. En este punto hay dos tipos de problemas: uno práctico y concreto: el estado actual de la neurofisiología, que no sería capaz de mostrar la identidad caso a caso de un estado mental con su correspondiente y único estado cerebral; y otro teórico: es distinto el soporte cerebral de un estado mental y su función dentro de su realización conductual. Esta es la línea que seguirá el funcionalismo para superar a la TI.

c) Y la tercera dificultad está relacionada con la hipótesis reduccionista que propone la $\mathrm{TI}$, presente en la tercera tesis de Feigl. Difícilmente se podrá admitir que todo se reduce a lo físico, como pretende la TI. A las tesis 
reduccionistas hay que replicar que es necesario distinguir entre dos niveles distintos: es cierto que lo físico es la condición de posibilidad de lo biológico y de lo mental; pero no es admisible, por no demostrable, que, producida la emergencia de lo biológico y de lo mental a partir de lo físico, estos niveles nuevos y superiores se reduzcan al anterior, y no tengan configuración y leyes de funcionamiento distintas y autónomas. Las leyes de la biología son autónomas de la física, así como las de la Psicología lo son respecto a la biología y a la física.

\subsection{El dualismo interaccionista de Karl Popper y de J. Eccles ${ }^{37}$}

Ambos autores coinciden en su postura dualista, aunque entre ambos existen diferencias muy significativas, que han Ilevado a algunos autores a considerar la postura de Popper no tanto como dualista sino como emergentista ${ }^{38}$. El resultado del diálogo entre los dos autores fue su libro conjunto, El yo y su cerebro ${ }^{39}$, compuesto por una primera parte filosófica, firmada por Popper; una segunda, de corte científico, firmada por Eccles (premio Nobel de medicina, y una de las máximas autoridades en neurofisiología); y una tercera de diálogo entre ambos, donde presentan sus opiniones sobre toda la temática cercana al tema mente-cuerpo, y donde se advierten las diferencias existentes entre ambos en temas centrales.
Para entender la postura de Popper, tenemos que hacer referencia a su teoría de los tres mundos, propuesta por primera vez en su artículo "Epistemología sin sujeto cognoscente ${ }^{\prime 40}$. Frente al fisicalismo, que concibe la realidad como un mundo material cerrado y configurado por leyes determinísticas, que para Popper constituye lo que denomina el Mundo 1, el filósofo austríaco defiende la existencia también del Mundo 2 y del Mundo 3. El Mundo 1 está formado por el conjunto de entidades físicas y biológicas existentes previamente y al margen de la acción humana. Pero el universo en el que estamos no está compuesto sólo por realidades físicas naturales, sino que también estamos rodeados de productos culturales creados por el ser humano. Es el Mundo 3. La conclusión es, por tanto, que si existe el Mundo 3, tan real como el Mundo 1, como lo prueban la realidad de las herramientas, las teorías matemáticas, filosóficas, estéticas, etc., tiene que existir el Mundo 2, la mente humana, que ha sido el sujeto del Mundo.

Tras demostrar la existencia de la mente, del Mundo 2, Popper se dedica a demostrar las insuficiencias de la teoría de la identidad, por su fisicalismo cerrado. Esta teoría, según Popper, se refuta a sí misma al pretender, por un lado, basarse en razonamientos lógicos, y negar, por otro, realidad a las leyes de la lógica (parte del Mundo 3). Además, para el fisicalista, como vimos, las leyes 
lógicas existen sólo como estados o disposiciones cerebrales (Mundo 1). Pero Popper piensa que el que se pueda impugnar la validez de un razonamiento, o se pueda descubrir el error de cálculo de una computadora, implica que, al margen de los procesos cerebrales movilizados en el razonamiento o de los mecanismos físicos que efectuaron el cálculo errado en la computadora, hay una entidad abstracta (las leyes de la lógica, que operan denunciando el error), que es, pues, práctica y eficaz, que no está encarnada (esto es, no pertenecen al Mundo 1), pero que ejerce efectos causales sobre el Mundo 1 (acusando, por ejemplo, la disfunción de la computadora). Estas normas lógicas no son entidades o propiedades físicas, pero repercuten en objetos físicos; son, pues, reales. Por eso que, en opinión de Popper, el materialismo cerrado no podrá nunca formular una teoría materialista de la lógica.

Otro aspecto que prueba la inconsistencia de las posturas materialistas es su incompatibilidad con la teoría evolucionista darwiniana, que defiende el salto cualitativo entre lo físico y lo mental. Si homologamos la mente con el cerebro, ignoramos el hecho de la evolución. En ese sentido, Popper defiende que la mente ha emergido (de ahí que, como decíamos, se suela situar también a Popper entre los emergentistas) en el proceso evolutivo, que nos muestra que de la materia inorgánica se ha dado el salto cualitativo a la materia viva, y de ahí a la mente. Claro que con esto la teoría evolucionista no explica cómo es posible este salto, sino que se limita a constatar la emergencia de esta nueva realidad, lo mental. Es evidente, como dice Popper, desde una postura epistemológica modesta, que la ciencia no explica nada, sino que se limita a constatar hechos.

En el modo como entiende el origen de lo mental, a partir de la emergencia desde la vida por complejificación del cerebro, Popper se desmarca de Eccles, quien, Ilevado por su credo católico (entendido de modo muy conservador, por cierto), defiende el origen de la mente en clave creacionista: el alma es creada directamente por Dios. El problema vendrá a la hora de explicar, como ocurre con todo dualismo, cómo interactúa el alma con el cerebro. Para explicar esto, Eccles elabora una modernización de la teoría cartesiana. Ya no se apela a la glándula pineal, sino a la conjugación e interacción entre grupos de neuronas, que forman unidades abiertas, y grupos de psiconas, supuestas unidades con las que estaría configurada la mente o el alma. Como puede verse, estos planteamientos son muy poco plausibles y muy difíciles de aceptar.

\subsection{Las posturas intermedias, unitarias o sintéticas}

\subsubsection{El funcionalismo ${ }^{41}$}

a) Las tesis centrales del funcionalismo

Esta teoría filosófica de lo mental 
surge para superar tanto el dualismo cartesiano como el conductismo y el monismo fisicalista de la TI. Si el conductismo había imperado durante medio siglo, la TI había sido la teoría más aceptada a continuación, siendo a su vez el funcionalismo la teoría hegemónica desde finales de los sesenta.

La dificultad mayor que advierten en el dualismo es la incapacidad de explicar la interacción entre mente y cuerpo. Al conductismo le atribuyen varias insuficiencias: a) el holismo de lo mental, es decir, la convicción de los funcionalistas de que, a diferencia de los conductistas, la mente funciona como un sistema complejo dotado de múltiples estados mentales internos interrelacionados entre sí, formando entre ellos un todo sistematizado. Por tanto, la conducta humana no puede explicarse sólo como una mera respuesta mimética y automática a un estímulo externo; b) los estados mentales no están constituidos por disposiciones a la conducta según circunstancias externas, sino que tales disposiciones son sólo un resultado de esos estados mentales. Es decir, los estados mentales causan la conducta. Ello significa que la mente humana es una realidad compleja y sistematizada, no reducible a una mera respuesta automática a los estímulos. Es lo que Putnam demuestra con su parábola intuitiva denominada de los superespartanos. Es decir, hay muchos momentos en la conducta humana en que un estado mental no se ex- presa con el esperado estado conductual (uno puede tener dolor de muelas y puede evitar expresarlo, y al revés: no tener dolor de muelas y simular que lo tiene). Por tanto, se da la realidad de lo mental, sin equivaler sin más a meros estados o disposiciones conductuales. Se puede, pues, postular estados mentales con ausencia de su manifestación externa o conductual.

A la TI le achacan el no distinguir entre la base física cerebral y la función que representa un estado mental. Con lo cual no cabría igualar el soporte cerebral con un estado mental, que realiza una función determinada en el conjunto de la conducta. Para explicarlo, J. Fodor trae el ejemplo de dos modos o estrategias de explicar una pieza del motor de un carro. Por ejemplo, el carburador. El teórico de la identidad cree que, para explicar qué es un carburador, es suficiente con indicarnos las diferentes partes y materiales con los que está compuesto. En cambio, el funcionalista, sin negar la pertinencia de esa explicación, se fija más en la función que el carburador tiene y realiza en el conjunto del motor. Así, son dos aspectos diferentes y complementarios: una cosa es saber de qué está hecha una cosa, y otra, saber qué función realiza en el conjunto del sistema.

Esta distinción sirve también para advertir el error de las tesis reduccionistas y eliminativistas, que pretenden que todo se reduce a lo físico. Para los funcionalistas, una 
cosa es el componente material de algo, y otra, su función. Esto, Ilevado al campo de lo mental, significa que una cosa es el conjunto de las aportaciones que la neurofisiología pueda hacernos sobre los estados cerebrales correspondientes a un estado mental y conductual, y otra muy distinta describir y señalar las características del estado mental correspondiente y su función en el conjunto del proceso conductual.

Los principales autores del funcionalismo son Hillary Putnam ${ }^{42}$, J. Fodor ${ }^{43}$ y David Lewis ${ }^{44}$. Suele también distinguirse entre un funcionalismo computacional, atribuido a Putnam, y un funcionalismo analítico, defendido por Lewis ${ }^{45}$, pero aquí no nos vamos a detener en tales distinciones, sino que me limitaré en presentar los aspectos más fundamentales del funcionalismo en general.

El funcionalismo, por tanto, centra su teoría en la noción clave de función y de descripción funcional. Una descripción funcional consistiría en la descripción de un proceso causal, esto es, indicar cómo una serie de causas o impulsos externos (inputs) dan lugar a una serie de respuestas (outputs) mediante un cierto tipo de procesos. Sistemas capaces de una descripción semejante son, por ejemplo, una máquina expendedora de billetes, de bebidas, o cualquier otro producto, o una cadena de montaje. El sistema mental puede describirse de modo similar, pudiendo advertirse a través de esta descripción los diferentes estados en los que puede hallarse un sistema, o nuestra mente.

Según esta concepción de la mente y de los estados mentales, la imagen que propone el funcionalismo (sobre todo el computacional, el primer Putnam) es la de la computadora. La diferencia que en ella se da entre el soporte físico (hardware) y el programa informático (software), sería similar a la que hay entre el cerebro y la mente respectivamente. En esta distinción, se ve claramente que, a diferencia de la $\mathrm{TI}$, una cosa es la necesidad del soporte físico cerebral, y otra que la mente y los estados mentales se reduzcan a estados cerebrales. En consecuencia, el funcionalismo prevé que un mismo estado mental pueda estar soportado o posibilitado por soportes físicos o cerebrales muy diversos, como serían los casos hipotéticos de una mente artificial (computadora), una mente humana, o una mente extraterrestre (un marciano, por ejemplo). Lo importante, pues, no es el soporte físico, sino el programa lógico, el sistema mental. Por tanto, cabe suponer que diferentes soportes permitan realizar idénticas funciones mentales: pensar, sentir dolor, tener una creencia, etc.

b) El funcionalismo y la inteligencia artificial $^{46}$

El funcionalismo ha dado lugar a la llamada inteligencia artificial, empeño en construir artificios inteligentes, con la pretensión que puedan imitar y suplir a las inteligencias humanas. Pero hay que dis- 
tinguir entre la inteligencia artificial débil y la inteligencia artificial fuerte. La primera considera que una computadora puede similar algunas funciones o estados de la mente humana, y la segunda defiende que se puede llegar a construir programas que sean iguales al pensamiento humano y a los diferentes estados de la mente humana.

Las tesis de la Inteligencia artificial (IA) tuvieron su origen en diferentes teorías y experimentos, pero el que más influyó fue el denominado test de Turing ${ }^{47}$, consistente en imaginar que se construye una computadora digital que interactúa con un ser humano. Si colocando dicha máquina y a un ser humano en dos salas distintas, y ante las respuestas a las preguntas que le envía el ser humano no es capaz de distinguir éste si el que responde es otro ser humano o una máquina, habríamos superado el test de poder construir una inteligencia artificial que simule actuar como una inteligencia humana.

A estas pretensiones de la IA fuerte se le han hecho muchas críticas, orientadas en la línea, en primer lugar, de que una máquina no podrá hacer más que aquello para lo que le programe un ser humano, por lo cual, no podrá nunca superar a su programador; otra línea crítica se orienta en la dirección de que las capacidades de la mente humana no se reducen a las que pueden reproducirse por una máquina digital ${ }^{48}$, sino que actúa muchas veces acortando el razonamiento, los algoritmos, y de este modo habría siempre aspectos de la mente humana que no podrían ser computarizados $^{49}$ (esta línea de reflexión estaría avalada por los avances de la teoría conexionista del cerebro, que muestran que el cerebro no funciona siempre al estilo de un sistema digital, sino también en conexiones paralelas, más complejas y difíciles de explicar); otra línea crítica afirma que la computadora, por más compleja y perfecta que se haga, es una abstracción que no puede asemejarse a la mente humana, en la medida en que no tiene sentidos para conectar e interactuar con el ambiente para recibir información y responder a los estímulos externos; así, la computadora es una mente abstracta, que sólo realiza actos supuestamente inteligentes porque el ser humano la programa para eso.

Las críticas que han dado más que hablar, y que han sido objeto de réplicas y contrarréplicas, son las que ha realizado el filósofo de Harvard, John Searle ${ }^{50}$. La objeción más seria al programa de la IA la realiza Searle con su Ilamado experimento de la habitación china. Imaginemos que, realizando el test de Turing, hemos construido una computadora tan perfecta que enviándole todo tipo de preguntas en chino las responde perfectamente, de tal modo que la computadora se comporta como si supiera chino. Para los defensores de la IA fuerte, ésta sería una prueba como para decir que esa computadora es capaz de hablar chino, y superaría el test de Turing. 
En cambio, para Searle, este experimento no demuestra que la máquina sabe hablar chino, sino que simplemente está programada para actuar como si supiera chino. La diferencia no es trivial, sino fundamental, porque en el lenguaje hay que diferenciar, señala Searle, entre la dimensión sintáctica y la dimensión semántica (además de la pragmática). Las computadoras tendrían dimensión sintáctica, pero no dimensión semántica, es decir, no saben ni son conscientes de lo que están haciendo. Esa es la diferencia radical entre, por ejemplo, un robot que está construido para aparcar a la primera un coche, y un ser humano que lo hace de forma deficiente. Pero si el robot le gana en precisión técnica, el ser humano sabe lo que está haciendo, y el robot no. Incluso, en escritos posteriores, Searle ha sido consciente de que había sido demasiado generoso con la computadora atribuyéndole la dimensión sintáctica. Pero la sintaxis, y demás dimensiones del lenguaje, sólo existen cuando hay una mente humana. Por tanto, la sintaxis con la que está construida la programación de una computadora, está sólo en la mente humana no en la máquina. Para mostrar esto, Searle pone el ejemplo de dos jóvenes que se ponen de acuerdo, para transmitirse un mensaje (por ej., si está o no el profesor en clase) conviniendo en que si una ventana de clase está abierta, significaría que el profesor no está, y si está la ventana cerrada, significaría que sí está. Sería absurdo que alguien dijera que la ventana habla y que es capaz de decir "sí" (está cerrada) y "no" (está abierta). Los objetos materiales (al igual que una computadora) son meras apoyaturas (significante) donde las mentes humanas sitúan sus mensajes y significados.

El argumento de la habitación china ha tenido muchas críticas y contestaciones, a las que Searle ha ido contestando y contraargumentando ${ }^{51}$. Pero no nos vamos a detener aquí en esta larga polémica. La síntesis de la polémica nos indica que, ante el problema de la IA fuerte, se sitúan, sobre todo, dos posturas: la de los reduccionistas, y la de los que consideran elemento diferenciador de la mente humana la consciencia y la posesión de la dimensión semántica. Se pregunta Searle por qué habrá gente que esté dispuesta a aceptar que si una máquina actúa como si fuera consciente o hablara chino, significa que es igual a ser consciente y a hablar chino. Y la conclusión es que todavía hay muchos críticos que no acaban de superar el prejuicio subyacente en la postura conductista, consistente en adoptar en el tema de lo mental una postura extrínseca de observación externa de la conducta (es decir, la postura de la tercera persona), sin aceptar que la conciencia es el elemento clave y diferenciador de la mente humana (enfoque de primera persona).

c) Insuficiencias o limitaciones del funcionalismo

No cabe duda de que el gran 
mérito del funcionalismo consistió en superar claramente las insuficiencias del conductismo y de la TI. Frente al conductismo, advirtió la objetividad de lo mental, con su teoría del holismo de lo mental, por la que se acepta que dentro de lo mental se dan diferentes estados mentales que interactúan entre sí. Y frente a la TI, no reduce los estados mentales a estados cerebrales, sino que distingue entre la base física cerebral (que está en diferentes estados) y la función de los diferentes estados mentales. Así, como ya dijimos, la función mental de abrir una puerta la pueden realizar sujetos construidos con elementos materiales diferentes: un ser humano, un robot, o un extraterrestre. En principio, podemos decir que los tres tienen el mismo programa inteligente, que les capacita para abrir la puerta, pero su base física no es la misma (neuronas, circuitos electrónicos, y la materia de que podamos imaginar estén compuestos los cerebros de los extraterrestres).

Pero la dificultad con la que se encuentran los funcionalistas consiste en explicar el modo como interactúa el programa (software) sobre la base física (hardware) para realizar sus funciones. A la hora de resolver la dificultad, los funcionalistas se dividen en dos posturas: a) los funcionalistas "de primer orden" (Lewis, sobre todo), y b) los "de segundo orden" (Putnam y la mayoría de los funcionalistas).

a) Para el funcionalista "de primer orden", la función depende de las características físicas o químicas de la realidad material en la que se apoya. Pero esta respuesta, que tiene la ventaja de ser más científica y verificable (en la medida en que no habría conflicto entre la tesis de la eficacia causal de la mente y la tesis de la completitud causal del mundo físico), le acerca de tal modo a la TI que no vemos cómo se diferencia de ella.

b) El funcionalista "de segundo orden", en cambio, considera que un estado mental es múltiplemente realizable, en la medida en que puede realizarse a través de diversos apoyos materiales. Por lo tanto, no puede darse una relación biunívoca entre una función y una única base material. Así, los estados mentales son autónomos de su base física. De este modo, como ya señalamos en su momento, este funcionalismo "de segundo orden" contiene argumentos eficientes para defender la autonomía de la psicología (caracterizada con propiedades de segundo orden, sobre las propiedades de primer orden o físicas). Pero este tipo de funcionalismo tiene la misma dificultad que el dualismo a la hora de explicar la eficacia causal de lo mental sobre lo físico. Imaginemos dos individuos que tienen el mismo estado mental (ver un objeto ante ellos que les interese atraparlo) pero tienen diferentes estados cerebrales. Según el funcionalista "de se- 
gundo orden", los dos realizarían la misma conducta, puesto que tienen el mismo estado mental, pero el sentido común pone en entredicho tal conclusión.

Una segunda dificultad del funcionalismo, común al conductismo y a la TI, está en que no sabe responder al problema denominado de "espectro invertido", que se da como caso ejemplar en el defecto denominado daltonismo. Aquí no se da correlación entre función y realidad física extrínseca. Pueden estar dos sujetos con el mismo estado mental (ver rojo), pero, si los estados mentales están funcionalmente caracterizados, los dos individuos están en distinto estado mental (están ante realidades físicas distintas).

Y la tercera dificultad consiste en no saber dar cuenta de la conciencia, esto es, de las experiencias internas de la mente, que coincide con el denominado problema de los qualia. Como veíamos con Searle, el funcionalismo no se ha desmarcado suficientemente en este punto de la óptica de tercera persona del conductismo y de la TI.

El gran problema del funcionalismo está en que, atrapado por la atrayente metáfora de las computadoras, ha caído en el error de pensar que el nivel de la programación (software) está totalmente aislado, separado y es indiferente a cualquier base material (hardware) en el que se apoya. Ahí está su error y las dificultades que siempre tendrá para explicar la eficacia causal de un programa sobre su base física. Y de hecho, podemos decir que cae en un dualismo larvado. Las dificultades del funcionalismo las pretenden superar las teorías emergentistas, como vamos a ver.

\subsubsection{Los emergentismos}

Las posturas emergentistas son muy plurales, y no siempre defienden posturas similares. Pero lo que tienen en común es que sí importa, a diferencia de los funcionalistas, la referencia a nuestro cerebro, esto es, a la base física de lo mental. En esta denominación de emergentismo se sitúan tanto Mario Bunge, como John Searle, en cierta medida, Karl Popper, y otros autores menos conocidos, como los españoles J.L. Pini$\operatorname{llos}^{52}$ y J. Monserrat ${ }^{53}$. Lo central del emergentismo, consiste en afirmar que la mente ha emergido o surgido de la evolución del cerebro. Por tanto, el cerebro sí importa a la hora de tener un concepto de lo mental. Así, para esta postura, la mente es el sistema o la estructura específica con la que está configurado nuestro cerebro, fruto del proceso de evolución biológica como ha sido formado. Ahora bien, el problema de esta teoría es que se puede defender esto y no coincidir después en qué idea se tenga de esa estructura mental, y con la ontología o antropología que se tenga de fondo.

Así, considero que se puede ser emergentista y al mismo tiempo defender la $\mathrm{Tl}$, el dualismo o una postura sintética o unitarista del ser 
humano. Todo esto condicionado a la suposición de que el emergentismo, en su sentido más estricto, no implica más que afirmar que la mente es un fruto de la evolución del cerebro. Veámoslo:

a) Emergentismo coincidente con la TI: el cerebro humano habría evolucionado de especies animales anteriores, y es lo que le habría capacitado para las específicas propiedades que posee. Pero la mente y los estados mentales se reducirán a estados cerebrales.

b) Emergentismo dualista (es el de Popper): la mente es resultado de la evolución y complejificación del cerebro, pero la mente sería distinta y funcionaría al margen de lo cerebral (Mundo 2), interactuando con él de la forma que fuera.

c) Emergentismo unitarista o sistemista: la mente es el sistema o estructura específica emergida en la evolución, y esa especial estructuración o complejidad de lo cerebral es lo que le permite a la mente humana poseer sus especiales características, y interactuar sobre la base neuronal del cerebro para dirigir la conducta.

En realidad, esta tercera acepción es la que se suele denominar propiamente emergentismo. Pero esta pluralidad de posibilidades es quizás una consecuencia de la gran ambigüedad que tiene la palabra emergentismo, como indica Pedro Laín Entralgo ${ }^{54}$. Para Laín, si consul- tamos un diccionario de español, emerger es la acción de salir a la superficie (por ejemplo, un submarino) una realidad que estaba oculta. Pero en esta emergencia, la realidad oculta no experimenta ningún cambio. Ahora bien, no es esto lo que quiere decir la teoría emergentista, puesto que en el proceso evolutivo lo que emerge, el cerebro, sí que experimenta novedad: se trata de un nuevo cerebro, una nueva estructura de lo cerebral, a la que denominamos "mente". Por tanto, lo central en el emergentismo que estamos considerando es la distinción entre el sistema y las partes del cerebro.

Vamos a presentar lo central de las posturas del emergentismo de Mario Bunge y de John Searle.

\section{a) El monismo emergentista de Mario Bunge ${ }^{55}$}

Para entender la postura de Bunge hay que comenzar por su noción de sistema, que define como una entidad compleja, compuesta por varios componentes que se relacionan entre sí de modo que se comportan como una totalidad unitaria y no como un mero agregado desordenado de partes. Se dan multitud de sistemas, cada una de las cuales tienen sus propias cualidades: fisiosistemas, quimiosistemas, biosistemas, psicosistemas, sociosistemas, etc.

Cada sistema tiene dos tipos de propiedades: resultantes y emergentes. Propiedades resultantes son las propiedades de las partes del sistema, y las emergentes son las del 
sistema en su globalidad. Para que un sistema sea tal, tiene que tener al menos, como es fácil suponer, una propiedad emergente.

Aplicado esto al cerebro, Bunge entiende que funciona como un sistema. Ahora bien, para entender esto de modo adecuado, Bunge diferencia entre tres modos de entender el funcionamiento del cerebro:

a) Neuronismo: el cerebro es un conglomerado de neuronas, por lo que para estudiar su funcionamiento basta con saber el funcionamiento de las neuronas;

b) Holismo: el cerebro funciona siempre y para todas sus funciones como un conjunto inseparable;

c) Sistemismo: el cerebro tiene diferentes funciones, unas propias de partes del sistema total (neuronas o subsistemas cerebrales) y otras, del conjunto total del sistema. Esta es la postura defendida por Bunge, entendiendo por mente al sistema total del cerebro, que debido a su complejidad posee las específicas cualidades que advertimos en una mente humana, entre las que destaca su prodigiosa plasticidad.

Así, la mente es el sistema cerebral, que no coincide con el mero funcionamiento físico del cerebro, como defiende la $\mathrm{TI}$, y que posee tal complejidad que, dada su plasticidad, puede reprogramarse (recursividad) y ser consciente de sí mismo.
Pero para Bunge la mente no es de naturaleza espiritual, ni la entiende al margen de la realidad física del cerebro. De ahí que su teoría la denomina monismo emergentista, porque se trata de defender un monismo de sustancias y un dualismo de propiedades. Es decir, es un monismo de sustancias, porque, según él, no hay más realidad que lo material; y dualismo de propiedades, puesto que el cerebro tiene propiedades físicas, pero también mentales, las propias del sistema en su totalidad. La mente es sólo una propiedad del cerebro (del sistema cerebral).

El planteamiento de Bunge es de gran interés, al plantear la interesante teoría sistemista del cerebro, pero lo que no resulta tan convincente es su concepción materialista de la realidad. Así, Popper le achaca la incompatibilidad entre su monismo materialista y la aceptación de la teoría evolutiva. Como vimos en su crítica a la $\mathrm{TI}$, para Popper, si la teoría de la evolución la tomamos en serio, tenemos que aceptar saltos cualitativos en ella, de tal modo que de lo físico llegamos, tras la complejificación de lo químico y biológico, a lo mental. $\mathrm{Y}$ aunque no sepamos definir la esencia de lo mental, sí parece que esta complejificación de la realidad nos induce a superar el materialismo y a defender un mundo más abierto que el concebido por el materialismo. Además, la concepción humanista de la antropología que defiende Bunge parece también que no se 
compagina muy bien con su materialismo cerrado, con su idea de lo material reducida a lo simplemente físico (fisicalismo).

\section{b) El emergentismo de J. Searle ${ }^{56}$}

Searle no se define explícitamente como emergentista, sino que define su postura como naturalismo biológico ${ }^{57}$, aunque su postura es sin duda en este apartado donde mejor se sitúa. En su crítica al funcionalismo, ya veíamos cómo le achaca no dar importancia a la base cerebral en la que se apoyan la mente y los estados mentales. Así, Searle considera que se da una estrecha relación entre los estados mentales y la base cerebral.

Para defender su postura, elabora una serie de afirmaciones o postulados, de los que voy a entresacar los más fundamentales ${ }^{58}$.

1) Los cerebros causan las mentes, en el sentido de que la mente y los estados mentales son el resultado de la actividad cerebral.

2) Causar las mentes o los estados mentales no hay que entenderlo en un sentido dualista, como si fueran dos realidades diferentes: la mente (como causa) y el efecto (como una realidad ontológicamente distinta). Decir que el cerebro es la causa de la mente es semejante a decir, por ejemplo, que la solidez de la superficie de madera de mi mesa es causada por la naturaleza de la madera (por la constitución física propia de la madera).
3) Así, las mentes no son realidades independientes del cerebro, sino resultado de su propia constitución. Por tanto, se puede mantener la noción funcional de los estados mentales y de la mente, pero unido a la realidad física del funcionamiento del cerebro.

4) Searle considera que las características más importantes de la mente son la consciencia, la subjetividad, la libertad, etc., rasgos que sólo son accesibles desde una mirada introspectiva. Por tanto, entiende que hay que superar el planteamiento conductista y cientista de tercera persona, y aceptar como necesario el enfoque introspectivo de primera persona.

Entiendo que esta postura es similar a la de Bunge, pero le falta quizás referirse explícitamente a cómo entiende la realidad de lo mental (en término de sistema), y cómo, en consecuencia, cabe explicarse la relación entre el sistema y las partes. La noción de sistema tiene la ventaja de hacer plausible la ausencia de identidad entre lo mental y la base neuronal del cerebro, aunque su relación es necesaria.

\subsubsection{El estructurismo dinámico de} Pedro Laín Entralgo ${ }^{59}$

Pedro Laín Entralgo, basándose en la filosofía de Zubiri y en los avances de las ciencias antropológicas, en especial la neurofisiología, denomina a su postura estructurismo, muy cercana al emergentismo. Se desmarca tanto de los dualismos 
como de los monismos fisicalistas por las razones que se han dicho en su momento, a través de otros autores. Considera también que el emergentismo tiene un nombre inadecuado para indicar los contenidos de lo que esta postura quiere defender, ya que emerger es sinónimo de salir a la luz algo que estaba oculto pero completamente constituido. Y el emergentismo hace referencia a la conformación de una realidad nueva (el complejo cerebro humano, y la mente, como estructura dinámica de la realidad humana) en un momento determinado del proceso evolutivo.

Tampoco le parece adecuado el concepto de brotar que usa a veces su maestro Zubiri para ese mismo fenómeno de emerger, porque brotar también es sinónimo de saltar el agua de una fuente, pero sin que suponga que en ese brotar el agua surja como una realidad nueva, sino como el momento de aparecer a la superficie tras estar antes oculta. Por eso, Laín considera que el concepto más adecuado sería el de constitucionismo. En el momento en que se da ese salto cualitativo, mutacional, tanto en el origen de cada ser humano, como en la conformación de un cerebro nuevo, se constituye ex novo una realidad nueva (aunque no de la nada). Así, podríamos definir a esta postura como constitucionismo estructurista, o como estructurismo dinámico, haciéndose referencia con estos dos términos a los dos momentos de la idea que se tiene de la mente: el dinámico (constitucionismo) y el estructural (estructurismo).

Esta teoría se configura sobre varias afirmaciones o ideas centrales:

a) Todo lo que hay está constituido por sustantividades, o realidades sustantivas, esto es, conjunto de notas que forman estructuras con suficiencia entitativa para existir. Cada estructura tiene notas adventicias y notas esenciales (constitutivas y constitucionales).

b) La realidad es dinámica, está dando de sí de modo constitutivo, no consecutivo. Así, se dan diversos dinamismos, denominados dinamismos de variación, alteración o alteridad, mismidad, suidad y socialidad o convivencia.

c) Dentro de las sustantividades vivas, el dinamismo de la mismidad hace que cada ser vivo sea un autos, en la medida en que posee un centro que controla y orienta su propia realidad; es decir, está dado a sí mismo, encargado de su propia supervivencia. Pero, por evolución, ese dinamismo no sólo genera otros seres vivos iguales, sino que en el dar de sí está la posibilidad (por mutación) de generar otras especies.

d) El modo como se producen esas mutaciones es a través de constituirse nuevas estructuras esenciales que configuran realidades nuevas (especies nuevas). Así, la 
propia realidad material viva da de sí realidades más complejamente estructuradas, hasta llegar a la especie humana.

e) El proceso evolutivo da de sí (aunque no por sí), por elevación, la especie humana. Este salto es tan cualitativamente diferente que Zubiri entiende que en él la materia viva da desde sí, pero no por sí, esa elevación. El que hace que desde la materia viva se produzca la elevación hasta lo humano es el cosmos, como la super-sustantividad que tiene el poder de hacer que la realidad ejercite y actualice sus potencialidades (la estructura es más que la suma de las partes, las notas, por lo que tiene un poder sobre ellas). Ahora bien, el cosmos nos lleva a la pregunta sobre el fundamento o esencia de sí, lo que nos plantea ya una pregunta metafísica y teológica. Pero no es el momento de profundizar en esa cuestión.

f) La sustantividad humana es entendida por Zubiri y por Laín como una única sustantividad o sistema único de notas, configurada por dos subsistemas, el soma u organismo y la psique, cada una de las cuales está constituida por su correspondiente conjunto de notas, pero que no forman una sustantividad autosuficiente, sino que la única sustantividad es la que constituye el conjunto total de cada ser humano. g) Por tanto, la psique es definida por Zubiri y por Laín como la estrutura dinámica de la realidad humana. Así, esa nueva estructuración de lo humano (configurado por dos subestruturas o dos subsistemas) es la que le constituye como una realidad diferente, dotada con habitudes diferentes y específicas de su especie. Por tanto, la realidad humana está dotada con la habitud de la intelección, una intelección sentiente, que le vierte constitutivamente a la realidad, pero no le aparta de su base sentiente, animal.

h) En definitiva, el concepto de mente equivale en Laín y en Zubiri al de una estructura, o sistema, dinámica. Lo específico de la realidad humana es su nueva estructuración o sistematización, no tanto en el nivel cerebral (que también), sino en el conjunto de su realidad. El problema está en especificar qué sea esa estructura o sistema. Por de pronto, no es una realidad con existencia independiente de la materialidad de lo corpóreo, pero sí de una naturaleza distinta de lo material. Laín utiliza para entenderlo el ejemplo de un conjunto matemático. El tres de un conjunto de tres manzanas no es una manzana más, ni es de la naturaleza de las manzanas. Pero no es sin más una realidad abstracta como en el conjunto matemático, sino que, al igual que afirmaba Bunge, todo sistema, para ser 
considerado como tal, tiene que tener al menos una propiedad emergente nueva. En la postura de Zubiri y de Laín, esa idea es mostrada al indicar que la estructura posee un plus (un poder) sobre las notas. Referido al tema de la mente o psique, la estructura o sistema psicorgánico nos permite comprender que las operaciones y cualidades de lo mental no se reducen a las de la base física del cuerpo o del cerebro, con lo que nos situamos más allá de los monismos materialistas o fisicalistas. Pero tampoco nos situamos en una postura similar al dualismo sustancialista, puesto que la estructura es siempre una estructura de las notas concretas, aunque no se reduce a ellas.

i) Por tanto, esta realidad tan compleja pero tan real es lo que parece ser lo mental, la psique, o como la queramos Ilamar. Así, la psique es un componente de lo humano, pero no autosuficiente, esto es, no es una sustantividad, sino un subsistema del sistema total que es cada ser humano. De ahí que no podamos aplicar a esta realidad la condición de ser inmortal, al estilo de Platón. Pero sí es suficiente como para apoyar en ella todas las tesis sobre la dignidad humana (ética y religiosa) que han defendido siempre los diferentes humanismos. De ahí que esta postura, al igual que los emergentismos, podrían servir de base óntica a la dimensión funcional que quiere indicarse cuando se afirma que el ser humano tiene "alma". Aunque tanto Zubiri como Laín indican que no utilizan esa palabra en su teoría por lo cargada que está de semántica dualista y religiosa.

\subsubsection{El neohilemorfismo}

También hay quien hoy en día considera válido el hilemorfismo de Aristóteles y de Santo Tomás. Esta postura se da entre quienes siguen considerando válidos los planteamientos escolásticos medievales, como ocurre entre algunos ámbitos católicos conservadores. En algunos casos, se apoyan en afirmaciones de algunos funcionalistas (como Putnam) que consideran que su noción formal de lo mental (programa sintáctico de computadora) es bastante similar al de forma aristotélica.

No cabe duda de que los planteamientos hilemorfistas son los más cercanos, dentro de las diferentes teorías de la historia de la filosofía, a las tesis actuales más válidas e interesantes de la actualidad, que hemos situado en el apartado sintético o unificador. El hilemorfismo se situó entre el materialismo reduccionista y el dualismo, pero se trata de una concepción metafísica ya superada y poco válida para constituir una filosofía que dialogue fructíferamente con la ciencia actual. Es lo que consideran tanto Zubiri como Laín. Para éstos, la idea de materia y de sustancia en la que está anclado el hilemorfismo, estaría superada por una metafísica 
y antropología apoyada en las categorías de materia y sustantividad, tal y como las entiende Xavier Zubiri.

En efecto, en la relación que se da en el hilemorfismo entre materia y forma, la materia actúa como realidad pasiva ante la acción configuradora de la forma. En cambio, para Zubiri y la ciencia física, la materia es constitutivamente activa, no pasiva. Además, la relación entre acto y potencia del hilemorfismo está también entendida como una relación demasiado cerrada, advirtiéndose en cambio que la realidad, más que estar orientada a su acto, está abierta a múltiples potencialidades y posibilidades.
Además, la filosofía aristotélica está anclada en la categoría de sustancia (hypokeimenon), propia de un dualismo ontológico, que habría sido superado por la categoría zubiriana de sustantividad, en la que la esencia no es una realidad misteriosa que se sitúa debajo de los accidentes, como soporte y apoyo de los mismos, sino en el conjunto de notas esenciales (constitucionales y constitutivas) que conforman y constituyen el fundamento, o esencia, de cada cosa real. De este modo, tendríamos que concluir que la filosofía hilemórfica, a pesar de tener elementos muy sugerentes, tendríamos que considerarla hoy día como fundamentalmente superada.

\section{8. ¿Hacia una convergencia de tradiciones en la actual filosofía de la mente?}

\begin{abstract}
( omo puede verse, la reflexión sobre lo mental o psíquico ha experimentado en las últimas décadas un intenso y profundo replanteamiento, en el que se han ido dando múltiples y variadas posturas, renovando casi las mismas posiciones que se habían defendido en momentos anteriores de la historia de la filosofía desde los griegos.
\end{abstract}

Aunque, como decíamos al principio, al hablar hoy en día de filosofía de la mente, o de nueva filosofía de la mente, se suele tener en consideración casi sólo las diversas posturas aparecidas dentro de la filosofía de ámbito anglosajón, a raíz de la superación del conductismo y la aparición de las ciencias cognitivas, entre los años cincuenta y setenta del siglo pasado, creemos sin embargo que sería una limitación reducirnos a ese ámbito y no situar esta problemática tan interesante tanto dentro de la tradición filosófica de siglos anteriores, como también dentro de las propuestas y teorías sobre la mente dentro de lo que los anglosajones denominan la tradición continental.

De hecho, si analizamos a fondo la historia de esta nueva filosofía de la mente y se tienen también en cuenta los nuevos centros de interés teóricos que hoy día ocupan a los filósofos de la actual filosofía de la mente, advertiremos, como vamos a indicar a continuación, que a 
medida que se va avanzando en la definición de lo mental, dentro de las polémicas entre las diversas teorías, advertimos que se vuelven a recuperar antiguas posturas $y$ conceptos que se creían superados y obsoletos.

Las dificultades que las teorías iniciales sobre lo mental han ido encontrando en al empeño de validar sus planteamientos, les ha ido advirtiendo de algunas graves insuficiencias en sus enfoques teóricos. Esas deficiencias fundamentales han sido las siguientes:

a) La negativa a enfocar el tema de lo mental desde la vertiente introspectiva o enfoque de primera persona, preocupados por un acceso científico y objetivo al problema. De ahí sus dificultades insolubles a la hora de resolver el problema de los qualia o en sus pretensiones de validez del proyecto de la IA fuerte (olvido o minusvaloración de la dimensión semántica del lenguaje).

b) La reivindicación de lo corpóreo, dentro de las teorías mentalistas, tanto para reivindicar la importancia de lo cerebral frente al funcionalismo como también, dentro del funcionalismo, a la hora de explicar la interacción entre el programa (software) y la base material (hardware). Un funcionalismo extremo, meramente formal, llevaría a una concepción idealista y solipsista de la realidad. Así, la IA, en su empeño por asemejarse a la inteli- gencia humana, parte del engaño de idear una especie de cerebro (programa y base material) que se sitúa aislado del mundo real, tanto en los estímulos que recibe (inputs) como en sus reacciones de respuesta (outputs).

c) En la recuperación de la corporalidad hay que situar también el creciente interés que en las investigaciones de la actual filosofía de la mente tiene la reflexión sobre los sentimientos. Es un síntoma de que la concepción tradicional de la mente se limitaba a considerarla reducida al ámbito de la racionalidad pura. Hoy día se habla tanto de "inteligencias múltiples" $(\mathrm{H}$. Gardner ${ }^{62}$, como de "inteligencia emocional" (Goldman) ${ }^{63}$, y de advertir la importancia de lo emocional sobre la racionalidad (A. Damasio) ${ }^{64}$. Tradicionalmente se consideraba que lo emocional era el ámbito de lo menospreciable, por irracional, campo distinto y al margen de lo racional. Hoy día se va siendo cada más consciente, por un lado, de la enorme riqueza y complejidad de lo emotivo, así como, por otro, de la estrecha relación entre lo racional y lo emocional, e incluso de la centralidad de lo emocional como base de lo racional. Según Damasio, lo emotivo es el sistema que la vida humana tiene, como restos de su pasado animal, de tomar rápidas decisiones, previas y más seguras que las racionales. Lo racional 
vendría después, para completar, desde la conciencia, el trabajo de desbroce previo que ya habría realizado, apoyado en la seguridad de lo instintivo, la estructura emocional que nos constituye por nuestra base biológica ${ }^{65}$. Vemos, pues, que la realidad de lo mental nos conecta con la compleja realidad unitaria que constituye al ser humano.

d) Y por último, en las disputas entre la perspectiva de la tercer persona, queriendo dar cuanta de lo mental desde la postura del observador externo (propia de la tradición anglosajona) y de la primera, con la centralidad del enfoque introspectivo (propia de la tradición continental, y también de Searle), va cobrando hoy día fuerza la perspectiva denominada de segunda persona (Antoni Gomila) ${ }^{66}$. Esta perspectiva nueva, que quizás habría que denominarla comunitarista o social (segunda persona del plural), abre horizontes insospechados y valiosísimos en el acercamiento al problema de lo mental. Es evidente que una comprensión adecuada del ser humano supone recoger, en una visión unitaria, la mirada objetiva externa y la introspectiva interna, y tal es la pretensión de esta estrategia de segunda persona como los intentos de la llamada filosofía de la acción ${ }^{67}$. En el estudio de la acción humana, se recoge tanto el estudio objetivo como la intencionalidad subjetiva del actor humano, pero no viéndola como un ámbito solipsista y cerrado, sino como un entrelazado de interacciones interpersonales y sociales, ámbito donde se configura y desarrolla el yo, cada persona humana. Por eso, estudiar la mente, la psique humana al margen de este entramado social es no entender nada de lo humano. Este enfoque comunitarista supone una concepción radicalmente diferente del ser humano, y la apertura a estrategias diferentes a la hora de estudiar los rasgos de la mente humana. Ya no habría que investigar al individuo aislado, sino dentro de actividades grupales, que son donde se advierten en su más honda realidad la esencia de la actividad mental. La adopción de esta nueva perspectiva no invalida las aportaciones más interesantes las dos posturas anteriores, que siguen siendo necesarias, pero se verían obligadas a reorientarse desde la nueva perspectiva de que hablamos.

En definitiva, estos temas, tan centrales dentro de la tradición filosófica continental (importancia de lo corpóreo, de la introspección, de la dimensión social del ser humano), están siendo objeto de reflexión y de recuperación por parte de la filosofía de la mente anglosajona, como consecuencia de las propias insuficiencias de las diversas teorías, advertidas tanto por la crítica interna como por filósofos de corte continental ${ }^{68}$. 
P ara terminar estas reflexiones sobre la filosofía de la mente en la actualidad, considero fundamental hacer referencia a la estrecha relación existente entre las diferentes teorías sobre la mente y el modelo antropológico que se haIla en su base o trasfondo. A pesar de esta realidad tan evidente, no siempre se explicita esta relación, ni tampoco se tiene en cuenta. Y sin embargo, hacer explícita esta relación aclara muchas cosas y sitúa la reflexión en su punto adecuado. Esto es importante de cara a establecer la relación existente entre una teoría de la mente y sus consecuencias éticas, antropológicas y sociológicas.

Cada teoría de lo mental conlleva, de modo implícito o explícito, una idea determinada del ser humano. Lo curioso es que en la nueva filosofía de la mente parece que se habla de lo mental al margen de una concepción unitaria de lo humano. Como si eso no se tuviera en cuenta, y, por tanto, como si no se tuviera que dilucidar una concepción de persona consecuente con la idea de lo mental. Y junto con una idea de ser humano, un modelo de sociedad y unas reflexiones éticas consecuentes a cerca de la dignidad humana.

Ya dijimos que en el contexto de la historia del problema, si nos remontamos a las culturas prefilo- sóficas (homérica y bíblica, sobre todo ésta), el tema del alma, la afirmación de que el ser humano tiene alma, surge precisamente dentro del empeño de dotar de dignidad ética, ontológica y religiosa al ser humano. A este empeño le llamábamos dimensión funcional del alma. Se dice que el ser humano tiene alma para indicar que posee un valor superior al conjunto de las realidades mundanas, lo que le hace a su vez imagen de Dios. A la hora de dar cuenta de qué entendemos por alma, esto es, al pretender dilucidar su dimensión óntica, se irán produciendo múltiples teorías y posibilidades. Así, el apoyo de las pretensiones éticas y humanistas tendrá que buscarse entre las diferentes teorías de lo mental que permitan implementar tales enfoques humanistas. En cambio, uno tiene la impresión de que en el trasfondo de las diversas posturas sobre la filosofía de la mente de base anglosajona, se da una concepción fundamentalmente mecanicista y reduccionista del ser humano. Se ve al ser humano como una máquina más o menos compleja, de la que interesa sólo descubrir su compleja estructura y funcionamiento. Pero parece que se olvida, y se deja de lado, la pregunta sobre su sentido, valor y dignidad.

En ese sentido, no se ve cómo pueden compaginarse las pretensiones de preeminencia ética del ser 
humano con teorías de lo mental como el conductismo y los diversos monismos fisicalistas, en la medida en que reducen al ser humano a una mera máquina física no diferente de los demás animales, a no ser que se sitúe tal diferencia en una complejidad meramente cuantitativa.

Y en relación al dualismo, por otro lado, lo que parece evidente es, al lado de la dificultad que supone defender la naturaleza independiente de lo espiritual y su interacción con lo corporal, la evidencia de que no se necesita ser dualista para asegurar la diferencia ontológica y ética del ser humano. Se puede ser humanista sin necesidad de defender la dualidad sustantiva del ser humano, puesto que el dualismo, como hemos visto, resulta

\section{NOTAS}

1 Cfr. Filosofía de la mente actual, Barcelona, Paidós, 1987 (2ª ed.: 2000), p. 53.

2 Cfr. Skinner, B.F., Ciencia y conducta bumana, Barcelona, Fontanella, 1971; Id., Más allá de la libertad y de la dignidad, Barcelona, Fontanella, 1982.

3 Cfr. Priest, S, Teorias y filosofías de la mente, Madrid, Cátedra, 1994, cap. II, "Conductismo lógico", pp. 55-87.

4 Cfr. Thorpe, W., Breve historia de la etología, Madrid, Alianza, 1982; Lorenz, Sobre la agresión. El pretendido mal, México, Siglo XXI, 1971; Lorenz, K./Leyhausen, P., hoy día muy difícil de sostener y de compaginar con los planteamientos científicos y filosóficos más actuales y convincentes.

De ahí que resulten más adecuados y aceptables los planteamientos intermedios o sintéticos, aunque necesitados de reorientar $y$ completar desde los nuevos avances sobre los sentimientos y la radical condición interpersonal y social del ser humano. Como vemos, pues, la filosofía de lo mental tiene que situarse de modo imprescindible dentro una visión completa del ser humano, que no olvide tampoco su esencial condición social y política. La filosofía de lo mental no puede, en definitiva, cultivarse y entenderse al margen de un correcto modelo antropológico que le sirva de fundamento y de apoyo adecuado.

Biología del comportamiento. Raíces instintivas de la agresión, el miedo y la libertad, México, Siglo XXI, 1971; Eibl-Eibesfeldt, I., Etología, Barcelona, Omega, 1979; Beorlegui, C., "El reto de la biología a la antropología. De la etología a la sociobiología", Letras de Deusto, 16 (1986), no 34, pp. 37-69.

5 Para todos estos acontecimientos históricos, cfr. Gardner, H., La nueva ciencia de la mente, o.c., caps. 2 y 3.

6 Cfr. para esta distinción Ruiz de la Peña, J. L., Las nuevas antropologias, Santander, Sal Terrae, 1983, p. 210.

7 Cfr. J. Gevaert, El problema del hombre, Salamanca, Ediciones Sígueme, 1991 ( $8^{\circ}$ ed.), pp. 71 y ss. 
Cfr. Priest, S., Teorias y filosofías de la mente, Madrid, Cátedra, 1994, pp. 25-33.

11 Cfr. Platón, Timeo, 90 A.

12 Gevaert, J., o.c., p. 78.

13 Cfr, Ibidem, pp. 74-76. .

14 Cfr. Gevaert, J., o.c., pp. 76-77.

15 Cfr. Ibídem, pp. 79-81; Priest, S., o.c., pp. 33-53.

16 Ibídem, p. 80.

17 Descartes, R., De methodo, A. T., VI, 558 (versión española en Discurso del método, o.c., p. 50); cfr. Meditaciones IX, 63. Cita tomada de Gevaert, J., o.c., p. 80.

18 Gevaert, J., o.c., p. 82.

19 D'Agostini, Franca, Analíticos y continentales. Guía de la filosofía en los últimos treinta años, Madrid, Cátedra, 2000; Sáez Rueda, Luis, El conflicto entre continentales $y$ analiticos, Barcelona, Crítica, 2002.

20 Cfr. Husserl, E., Investigaciones lógicas (1900-1901), La idea de fenomenología (1907), La filosofía como ciencia estricta (1911), Ideas... (1913), Meditaciones cartesianas (1931), y La crisis de las ciencias y la fenomenología trascendental (1936), publicadas en Gesammelte Werke (Obras completas), Lovaina, 23 vols., 1950-1980. Cfr. GOMEZ ROMERO, I., Husserl y la crisis de la razón, Madrid, Cincel, 1987; GÓMEZ-HERAS, José M. G., El a priori de la ciencia de la vida, Barcelona, Anthropos, 1989.

21 Cfr. López Sáenz, Carmen, "Subjetividad trascendental como intersub- jetividad trascendental en la fenomenología de Husserl”, Pensamiento, 57 (2001), $\mathrm{N}^{\circ} 218$, pp. 251-273.

22 Barcelona, Península, 1975.

23 Cfr. Merleau-Ponty, M., La fenomenología y las ciencias del hombre, Buenos Aires, Ed. Nova, 1969; Id., La estructura del comportamiento, Buenos Aires, Hachette, 1976; Id., Sentido y sinsentido, Barcelona, Península, 1977; Bello, Eduardo, De Sartre a Merleau-Ponty. Dialéctica de la libertad y el sentido, Murcia, Universidad de Murcia, 1979.

Cfr. Sartre, J.-P., El ser y la nada, Buenos Aires, Losada, 1966.

Cfr. Schöpf, A., "El problema almacuerpo desde la perspectiva fenomenológica y psicoanalítica”, Diálogo Filosófico, 8/1 (1992), pp. 4-18.

Cfr. Skinner, B. F., Más allá de la libertad $y$ de la dignidad, Barcelona, Fontanella, 1972. .

27 Cfr. Skinner, B. F., Walden dos, Barcelona, Fontanella, 1967.

28 Cfr. Priest, S., Teorias y filosofías de la mente, o.c., cap. II, pp. 55-87; Martínez-Freire, P. F., La nueva filosofía de la mente, Barcelona, Gedisa, 1995, caps. 3 y 4.

Cfr. Rabossi. E., "Teoría de la identidad mente-cuerpo", en Broncano F. (ed.), La mente humana, Madrid, Trotta, 1995, pp. 17-42; Candela, J. A./Cañón, C./Hortal, A., "Monismos, Dualismos y Emergentismos", en Dou, A. (ed.), Mente y Cuerpo, Bilbao, Mensajero, 1986, pp. 19-64.

31 Cfr. Ruiz de la Peña, J. L., Las nuevas antropologias, Santander, Sal Térrea, 1983, pp. 138-155. 
Cfr. Rabosi, E., "La tesis de la identidad mente-cuerpo", o.c.; en Broncano, F. (ed.), La mente humana, Madrid, Trotta, 1995, pp. 17-42; 23; Candela, J.A./Cañón, C./Hortal, A., o.c., pp. 19-32.

33 Cfr. Smart, J. J. C., "Sensations and Brain Processes", Philosophical Review, 68; incluido en Borst, C.V. (comp.), The Mind-Brain Identity Theory, MacMillan, London, 1970.

34 Cfr. Feigl, H., The "Mental" and the "Physical", Minneapolis, $1967 / 2^{\mathrm{a}}$ ed.),

35 Sigo a J. L. Ruiz de la Peña, o.c., pp. 138 y ss.

36 Cfr. Rabossi, E., o.c., pp. 31 y ss.

37 Cfr. Ruiz de La Peña, J. L., o.c., pp. 174-199; Candela, J.A./Cañón, C./Hortal, A., o.c., pp. 33-44.

38 Cfr. Candela, J.A./Cañón, C./Hortal, A., o.c., pp. 51-55.

39 Barcelona, Labor, 1980.

40 Publicado en Conocimiento objetivo, Madrid, Tecnos, 1974, pp. 106-146.

${ }^{41}$ Cfr. García-Carpintero, M., "El funcionalismo”, en Broncano, F. (ed.), La mente humana, o.c., pp. 43-76; Pujadas Torres, Luis M., La ascensión y caída de la teoría funcionalista de la mente, Palma de Mallorca, Universitat de les Illes Baleares, 2002; Priest, S., o.c., cap. V, pp. 163-181; Martínez-Freire, P. F. , o.c., caps. 7 y 8, pp. 77 y ss.

42 Cfr. Priest, S., o.c., 168-176.

43 Cfr. Fodor, J., La explicación psicológica, Madrid, Alianza, 1980 (texto original, 1968).

44 Cfr. Priest, S., o.c., pp. 176-181.

45 Cfr. García-Carpintero, M., o.c., pp. 54 y ss.
Cfr. Ross Anderson, A. (ed.), Controversia sobre mentes y máquinas, Barcelona, Tusquets, 1984; Turing, A.M./Putnam, H./Davidson, D., Mentes y máquinas, Madrid, Tecnos, 1985; Searle, John, Mentes, cerebros y ciencia, Madrid, Cátedra, 1985; Gardner, H., La nueva ciencia de la mente, o.c., cap. 6; Martínez-Freire, P. F., o.c., cap. 8, pp. 99 y ss.

47 Cfr. Turing, A. M., “¿Puede pensar una máquina?”, en Turing, A.M./ Putnam, H./Davidson, D., o.c., pp. 15-60. Este trabajo apareció, con el título "Computing Machinery and Intelligence", en la revista Mind, 59 (1950), $\mathrm{N}^{\mathrm{O}} 236$

48 Véanse las críticas de Hubert Dreyfus y Joseph Weizenbaum: cfr. Martínez-Freire, P. F., o.c., pp. 105112.

Cfr. Penrose, R., L, La nueva mente del emperador, Madrid, Mondadori, 1991.

50 Cfr. Searle, J., Mentes, cerebros y máquinas, o.c.; Id., El misterio de la conciencia, Barcelona, Paidós, 2000.

51 Cfr. Liz, Manuel, Perspectivas actuales en filosofía de la mente, Tenerife, Gobierno de Canarias, 2001, caps. $5^{\circ}$ (J. Searle) y $6^{\circ}$ (Patricia y Paul Churchland).

52 Cfr. Pinillos, J. L., La mente humana, Madrid, Salvat, 1969 (Madrid, Temas de Hoy, 1991).

53 Cfr. Montserrat, J., Epistemología evolutiva y teoría de la ciencia, Madrid, UPCO, 1987; Id., La percepción visual. La arquitectura del psiquismo desde el enfoque de la percepción visual, Madrid, Biblioteca Nueva, 1998.

54 Cfr. Nuestro cuerpo. Teoría actual, Madrid, Espasa-Calpe, 1988; y 
Cuerpo y alma, Madrid, Espasa-Calpe, 1991.

55 Cfr. Bunge, M., The Mind-Body Problem. A Psychobiological Approach, Oxford, 1980 (trad. El problema mente-cerebro, Madrid, Tecnos); Id., Epistemología, Barcelona, 1980; Ruiz de la Peña, J. L. , Las nuevas antropologias, o.c., pp. 156-173.

56 Cfr. Searle, John, Mentes, cerebros y ciencia, Madrid, Cátedra, 1985; Id., El misterio de la conciencia, Barcelona, Paidós, 2000; Id., Mente, lenguaje $y$ sociedad, Madrid, Alianza, 2001.

57 Cfr. Searle, "Mentes y cerebros sin programas", en Rabossi, E. (comp..), Filosofía de la mente y ciencia cognitiva, Barcelona, Paidós, 1995, pp. 413-442.

58 Cfr. Searle, J., Mentes, cerebros y ciencia, o.c., p. 45.

59 Además de los dos libros citados más arriba, en la nota 53, Laín ha expresado su postura en otros libros como Alma, cuerpo, persona (1995), Idea del hombre (1996), y Qué es el hombre. Evolución y sentido de la vida, Oviedo, Ediciones Nobel, 1999.

Cfr. Laín, Pedro, Qué es el hombre. Evolución y sentido de la vida, o.c., pp 29-67; y 135 y ss.; Id., "El problema alma-cuerpo en el pensamiento actual”, en Mora, Francisco (ed.), El problema cerebro-mente, Madrid, Alianza, 1995, pp. 17-35.
Aunque J. L. Ruiz de la Peña no se sitúa dentro del neo-hilemorfismo, sí considera como legítima y actual esta teoría: cfr. Las nuevas antropologías, o.c., capítulo último.

62 Cfr. Gardner, H., Inteligencias múltiples, Barcelona, Paidós, 1985.

Cfr. Goleman, Daniel, Inteligencia emocional, Barcelona, Kairós, 1996.

Cfr. Damasio, A. R., El error de Descartes, Barcelona, Crítica, 1996.

65 Cfr. Broncano, F, "Las emociones: territorios intermedios en la mente", y Moya, C. J., "Emociones, racionalidad y responsabilidad", ambos en Martínez-Freire, P. F (ed.)., Filosofía actual de la mente, Málaga, Universidad de Málaga (Revista Contrastes), 2001, pp. 217-240 y 241-255, respect.

66 Cfr. Gomila, A., "La perspectiva de segunda persona: mecanismos mentales de la intersubjetividad", en Martínez-Freire, P. F. (ed.), Filosofía actual de la mente, Málaga, Universidad de Málaga (Contrastes), 2001, pp. 65-86.

Cfr. Ricœur, P., Yo mismo como otro, Madrid, Siglo XXI, 1996.

68

Cfr. Martínez-Freire, P. F. (ed), Filosofía actual de la mente, Suplemento 6 (2001) de Contrastes (Málaga), 2001. 